\title{
An Investigation of the Enolization and Isomeric Products Distribution in the Water Promoted Aldol Reaction of Tropinone and Granatanone
}

\author{
Ryszard Lazny, Artur Ratkiewicz, Krzysztof Brzezinski, \\ Aneta Nodzewska, and Katarzyna Sidorowicz \\ Institute of Chemistry, University of Bialystok, ul. Ciolkowskiego 1K, 15-245 Bialystok, Poland \\ Correspondence should be addressed to Artur Ratkiewicz; artrat@uwb.edu.pl
}

Received 16 August 2016; Revised 12 November 2016; Accepted 16 November 2016

Academic Editor: Teodorico C. Ramalho

Copyright (C) 2016 Ryszard Lazny et al. This is an open access article distributed under the Creative Commons Attribution License, which permits unrestricted use, distribution, and reproduction in any medium, provided the original work is properly cited.

\begin{abstract}
The exo,anti/exo,syn-diastereoselectivity of water promoted direct aldol reactions of tropinone and granatanone (pseudopelletierine) is strongly dependent on the amount of water added and aromatic aldehyde used. DFT methods were applied to calculate the free energies of tropinone and granatanone enols, transition states, and isomeric aldol products. A theoretical model was verified by comparison of results from several DFT methods and functionals with experiments. The 6-31g(d)/CPCM method proved most suited to the problem, although all methods tested predicted similar trends. Explicit inclusion of a water molecule bonded to the amino ketones resulted in increased stability of the enol forms. The dependence of the anti/syn-diastereoselectivity on the amount of water used may be rationalized on the basis of change in the polarity of the reaction medium. The predicted stabilities of competing products agreed with experimental results supporting the notion of thermodynamic control. The isomeric products distributions for the aldol reaction of several aromatic aldehydes in solventless (neat) conditions were accurately calculated from free energies of the aldol addition step in the gas phase using B3LYP/6-31g(d) method and in aqueous conditions using the CPCM-B3LYP/6-31g(d) model. Our methodology can be useful for predicting the outcome of this type of aldol reactions.
\end{abstract}

\section{Introduction}

The organocatalytic aldol reaction [1] is one of the most powerful methods for forming C-C bonds in a highly stereocontrolled manner. Since the pioneering work of List's group [2] concerning the application of (L)-proline as a catalyst, a variety of amines have been designed as organocatalysts for aldol reactions [3] aiming at high efficiency, wide applicability, relatively low cost, and availability from the chiral pool. Primary and secondary amines are the most popular NH-functionalised organocatalysts $[3,4]$. The typical mechanism of catalysis of a direct aldol reaction based on the formation of (Z)- or (E)-enamine intermediates is well known $[4,5]$. The use of tertiary amines as catalysts is rather underrepresented. However, tertiary amine catalysts involving, for example, DBU [6], DIPEA [6], cinchona alkaloid derivatives $[6,7]$, or pyridine $[8,9]$, have been applied in direct aldol reactions, typically under anhydrous conditions. The role of nonenamine catalysts often remains unclear, but it has been assumed that these amines often act as general base catalysts. After Pihko and coworkers [10] demonstrated that water increases efficiency of $(\mathrm{L})$-proline catalysed aldol addition, the study of reactions in the presence of water had intensified, including those catalysed by tertiary amines, for example, DABCO [11]. Investigations involved a combination of computational and experimental methods or computational studies (especially based on DFT methods) [12]. However, these studies have not involved reactions contingent on the presence of water and promoting role of tertiary amine functionality present in the substrate/product itself.

Chiral lithium amide promoted aldol reaction of tropinone (1, 8-methyl-8-azabicyclo[3.2.1]octan-3-one) has been used by us $[13,14]$ and others $[15,16]$ as a diastereoselective and enantioselective key step in several syntheses of tropane derivatives, mostly natural tropane alkaloids. 
Before our preliminary communication on aldol addition of tropinone and granatanone (pseudopelletierine, 2, 9-methyl9-azabicyclo[3.3.1]nonan-3-one) to aldehydes (Scheme 1) in the presence of water [17], the only method for accessing these exo,anti-aldols $[18,19]$ or related nor-analogues $[20,21]$ was reactions promoted by lithium amide bases under anhydrous conditions. Moreover, our solventless reaction in the presence of small (ca. equimolar) amounts of water [17] is the only practical method for preparation of the exo,syn isomers $[18,22]$. Because no chiral additives are present in the reacting mixture, the reaction is diastereoselective but not enantioselective and provides products in the racemic form.

Herein, we disclose in full our theoretical investigations on stereoselectivity of tropinone and granatanone aldol reactions, computations of reaction parameters, and isomer stability, as well as suitability of computational methods at different levels of theory for rationalization of the results of these "green" reactions.

\section{Results and Discussion}

We proved that water and a tertiary nitrogen atom built into substrate are necessary for the effective, direct, and spontaneous aldol reaction of cyclic ketones with aromatic aldehydes [23]. In a preliminary communication, we proposed that in the reactions of tropinone and granatanone with benzaldehyde the origins of the stereoselectivity may be found in thermodynamic equilibration of the internal hydrogen bond stabilized conformers $[17,24]$ of the competing isomeric products (Scheme 1), unless preferential crystallization of solid products is involved. We found that calculated stabilities of the isomers and their distributions could accurately reproduce experimental results for reactions without solid product deposition. Interestingly, gas-phase calculations best approximated solventless (neat) reaction conditions [24].

Therefore, with hopes of possibly tuning and expanding the scope of the method on prediction of reactions feasibilities with new reactants, we found it worthwhile to further study the theoretical methods for description of the processes. A good correlation of DFT results and experiments could possibly allow for prediction of outcomes of such reactions.

\subsection{Enolization and Hydration of Cyclic $\beta$-Amino Ketones} in the Presence of Water. As such reactions had no precedents in the literature, we approached the problem by comparing experimental results with data obtained in a theoretical manner, analogous to the one used by Houk for acetone reaction and invoking ketone enol [26]. Water catalysed tautomerization has been studied by experimental [27] and computational methods [28, 29]. In our case one could assume involvement of the general base catalysis in tropinone and granatanone enolization [30]. However, the success of the reactions is dependent on the presence of the amine nitrogen in the substrate and $\mathrm{pH}$ of the reaction medium (see Supplementary Material available online at http://dx.doi.org/10.1155/2016/4674901) (optimized geometries and frequencies of the invertomers in methanol). This suggests involvement of hydroxide ion (specific base). Ketone enolization needs base or acid catalysis [31] and enolization in the presence of tertiary amines in water is commonly known [32, 33]. Aqueous tropinone (1) and granatanone (2) solutions $(0.1 \mathrm{M})$ show $\mathrm{pH}$ ca. 10 and 9.2, respectively. This corresponds to calculated $\mathrm{pK}_{b} 7.0$ and 8.6 for these bases; thus, granatanone is a slightly weaker base than tropinone (both amino ketones are weaker than closely related amino alcohol, tropine (estimated $\mathrm{pK}_{b}$ ca. 3.8) or triethylamine $\left(\mathrm{pK}_{b}\right.$ ca. 3.4)). Nonetheless, both amino ketones are basic enough and sufficiently soluble to give considerable concentration of hydroxide ions (strong specific base) and, as a result, effect relatively rapid ketone enolization in water. This is experimentally indirectly observable through spontaneous $\alpha$-deuteration in $\mathrm{D}_{2} \mathrm{O}$ solution (see supporting information) (exchange of the axial hydrogens in the $\alpha$-position in granatanone is faster (ca. $90 \%$ exchange for deuterium in $2 \mathrm{~h}$ ), then in tropinone (ca. $70 \%$ deuteration in $2 \mathrm{~h}$ ) as observed by ${ }^{1} \mathrm{H}$-NMR spectroscopy). The spontaneous deuteration is faster than aldol reaction, the rate of which depends also on reactivity of the aldehyde used, indicating that the rate limiting step of the whole process is not the enolization. Thus, addition of water results in a relatively fast self-enolization of 1 and 2, in the observed aldol reaction time frame [17]. The question whether the presence of water influences the ketone-enol preequilibrium, changing enol concentration in these reactions, needs to be addressed, for example, by computations (vide infra).

Negative results obtained under the same aqueous conditions with other reactive electrophiles (see supporting information), including electrophiles known to give products in reaction with tropinone enolates (e.g., cyanoformate and chloroformates $[19,34])$, suggest that aldehydes are privileged reagents in this context.

The appreciation of the configurational preferences of $\mathrm{N}$-methyl group in tropinone and granatanone is vital for understanding dissimilarities in their reactivity. Considering enolization of the $\beta$-amino ketones in the presence of water one could assume involvement of hydrated forms. The studies on the hydration of tropinone have been conducted in Cocinero's group. They applied Fourier-transform microwave spectroscopy and theoretical calculation to show that the tropinone $\cdots \mathrm{H}_{2} \mathrm{O}$ monohydrated complex is stabilized by a hydrogen bond formed between one molecule of water and the tertiary amine group [35]. Furthermore, their results agree with our findings that an equatorial $\mathrm{N}$-invertomer of tropinone predominates in aqueous solution [36]. We found also that other $\mathrm{N}$-alkyl substituted nortropinones have a tendency to appear in equatorial conformation [37, 38]. However, the opposite axial configuration of the $\mathrm{N}$ methyl group was observed in a crystal of tropinone without a molecule of water [39]. Our previous NMR study on equatorial/axial position of the $\mathrm{N}$-methyl group indicated axial preference in granatanone (pseudopelletierine) in water [36]. The same axial position of N-methyl substituent in the crystal of granatanone with and without a molecule of water was observed by us in this study. We observed for the first 


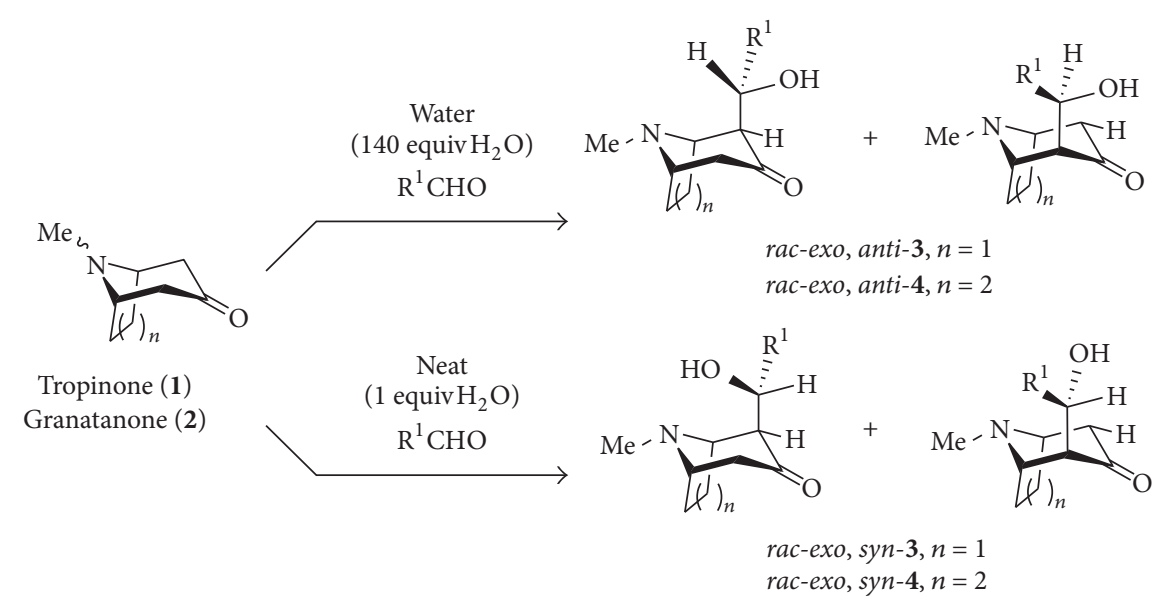

Scheme 1: Water dependent stereoselective formation of either exo,anti or exo,syn-aldols of tropinone and granatanone [17].

time that granatanone has a tendency to crystalize from $n$ hexane/diethyl ether mixture, without exclusion of moisture, as a hemihydrate $\left(2 \cdot(1 / 2) \mathrm{H}_{2} \mathrm{O}\right)$; thus, the granatanone crystal without a molecule of water was obtained from dried solvents.

Two crystal structures of 9-methyl-9-azabicyclo[3.3.1]nonan-3-one (2) and its hemihydrate $\left(2 \cdot(1 / 2) \mathrm{H}_{2} \mathrm{O}\right)$ have been experimentally determined by single crystal $\mathrm{X}$-ray diffraction. The crystal structure of 9-methyl-9-azabicyclo[3.3.1]nonan-3-one (Figure 1) contains two granatanone molecules in the asymmetric unit, which suggests a classical hydrogen bond network within a crystal lattice. The crystal structure of 9-methyl-9-azabicyclo[3.3.1] nonan-3-one hemihydrate (Figure 2) contains two granatanone units and one water molecule in the asymmetric unit. A water molecule is involved in intermolecular interactions with two symmetry independent molecules and two hydrogen bonds: O1H1B $\cdots$ N9 with O1 $\cdots$ N9 $=2.934(2) \AA$ and O1-H1B $\cdots$ N9 $=168(3)^{\circ}$ and $\mathrm{O} 1-\mathrm{H} 1 \mathrm{~A} \cdots \mathrm{N} 19$ with O1 $\cdots \mathrm{N} 19=2.862(2) \AA$ and $\mathrm{O} 1-\mathrm{H} 1 \mathrm{~A} \cdots \mathrm{N} 9=174(3)^{\circ}$ are generated between a water molecule and heterocyclic nitrogen atoms. In both crystal structures, granatanone molecules show a very similar conformation. In all cases, piperidine and piperidinone rings adopt a chair conformation with very similar puckering parameters [40], shown in Table 1 in Supplementary Material.

The question arises how the bonding of the nitrogen to water, observed in the crystals, or an alternative bonding of the carbonyl oxygen to water may influence the enolization equilibrium of the bicyclic amino ketones.

2.2. Evaluation of Computational Methods. To assess the accuracy of different basis sets/DFT functionals combinations in relation to our systems, we performed systematic benchmark calculations. Previously [24], we found the B3LYP/6-31G(d) [41, 42] method as a good tool for investigating the stereoselectivity in the aldol reaction of the bicyclic amino ketones in the presence of water. The B3LYP method with larger basis set $(6-311++G(3 d, 3 p)[43])$ and the BH\&HLYP/cc-pVDZ [44, 45] method were also successfully validated in investigating tropinone and granatanone $\mathrm{N}$ invertomers equilibria [36]. Recently, a $\operatorname{M0n}(n=5,6)$
[46] family of functionals was introduced and widely used in different areas of chemistry [46]. Therefore, because of the excellent performance with respect to the prediction of relative energies for gas-phase monosaccharide isomers [47], we also included this method in our assessment. Overall, we employed six different DFT functional/basis set combinations, including one tested for organocatalytic reactions, B3LYP/6-31(d,p) [48]. Considering the relative stability of four $\mathrm{H}$-bond stabilized forms of product, shown in Figure 3, has been found successful for rationalization of stereochemical outcome of this reaction [24]. Using the same approach, the results of the current method evaluation are presented in Table 1 (including deviation from experimental data) and are plotted in Figures 4 and 5. It is evident that in the gas phase all the methods pointed out to significant dominance of the HB-N form of exo,syn-aldols (Figures 4 and 5). For the water phase, the calculated ratios differ fairly significantly depending on the method used, although both HB-N forms dominate in all cases (see Figures 4 and 5). To assess the influence of increasing the basis set used, the B3LYP/6-311++g(3d,3p) method was also used to compare with the lower level calculations. Surprisingly, the simplest and the least demanding B3LYP/6-31g(d) can be credited with highest confidence in the quantitative respects of the issue investigated, whereas the worst agreement was observed for the reportedly highly accurate M062X functional. It may also be concluded that larger than $6-3 \lg (\mathrm{d})$ basis sets with diffuse functions (e.g., 6-31G(d,p) and 6-311++G(3d,3p)) do not improve results.

Satisfactory (but worse than for B3LYP) accuracy was also noted for the BH\&HLYP functional. Comparison of calculated MAD of the B3LYP for the simplest 6-31g(d) (A) and the most computationally demanding $6-311++\mathrm{G}(3 \mathrm{~d}, 3 \mathrm{p})$ (B) basis sets is shown in Tables 2 and 3. In general, the data (Tables 2 and 3 ) show that the structure of the aldehyde used should not affect the conclusions of method evaluation. The agreement of the B3LYP/6-31g(d) results with experimental results confirmed this functional/basis set combination as 

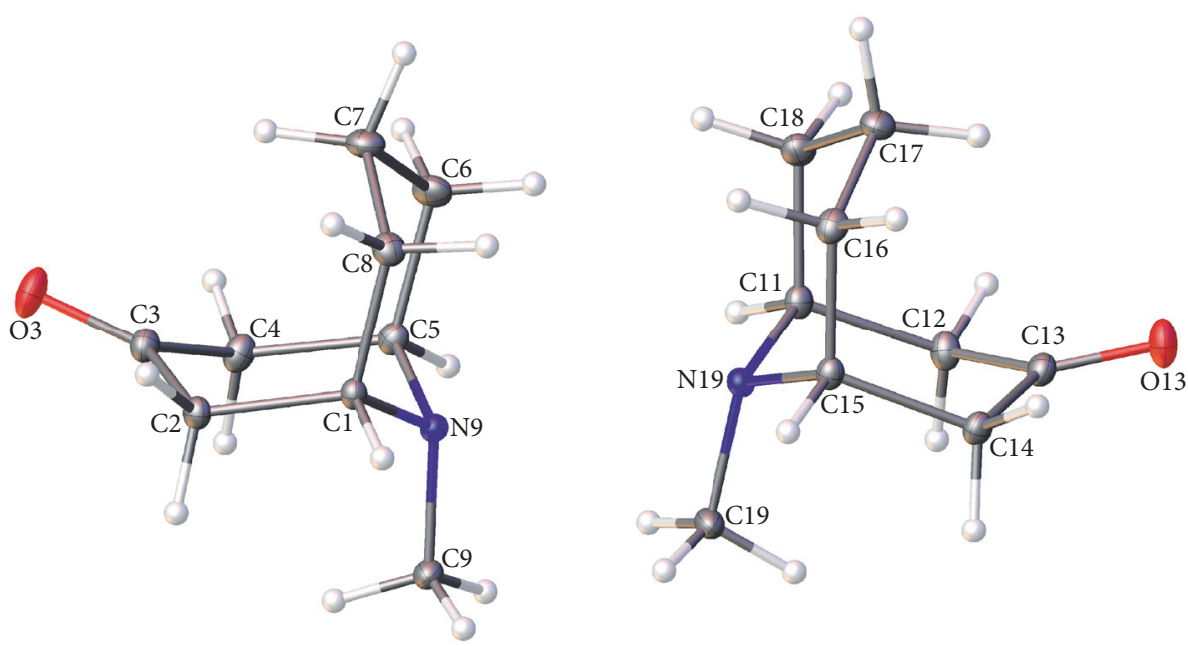

Figure 1: The view of the asymmetric unit of 9-methyl-9-azabicyclo[3.3.1]nonan-3-one. Displacement ellipsoids are drawn at the 30\% probability level. The figure was prepared with OLEX2 [25].

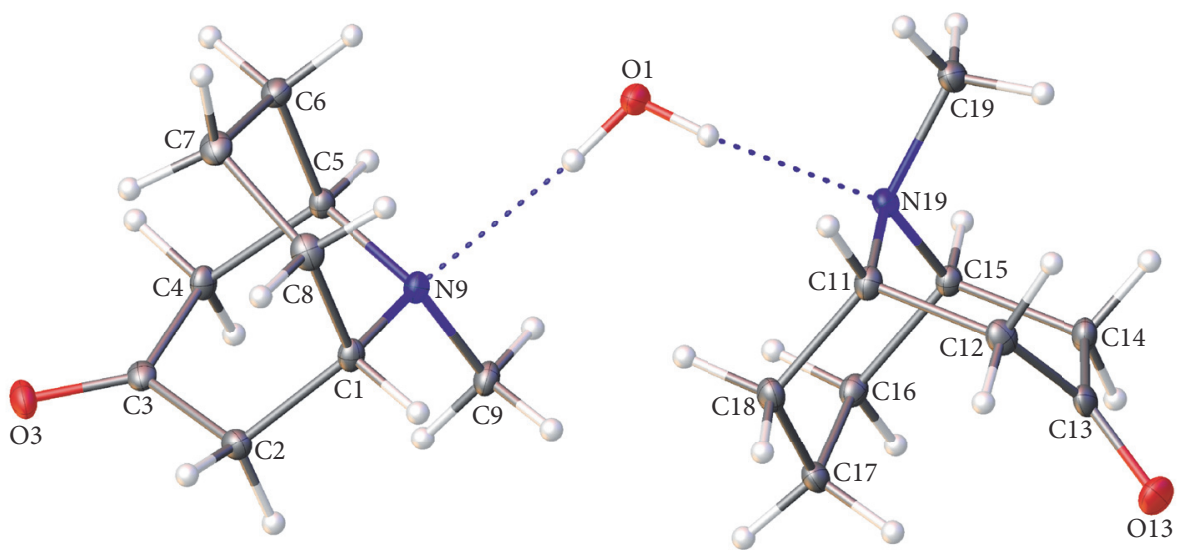

Figure 2: The view of the asymmetric unit of 9-methyl-9-azabicyclo[3.3.1]nonan-3-one hemihydrate. Displacement ellipsoids are drawn at the $30 \%$ probability level. Dashed lines represent hydrogen bonds. The figure was prepared with OLEX2 [25].

the most adequate for modelling the progress of these aldol reactions; thus, this method was used in the discussion through this study.

2.3. Computational Study of the Reaction. To consider all the possible forms of reacting donor species (Figure 6), we calculated the $\Delta G$ of the enol forms 5 and $\mathbf{6}$, the zwitterionic forms (protonated enolates, 7 and 8), a dimer of protonated tropinone and tropinone enolate (9), and the hydrated zwitterionic forms (10 and 11). At the B3LYP/6$3 \lg (\mathrm{d})$ level the zwitterionic forms were estimated to be much higher in energy than the enol forms, by 11.2 and 13.2 in water for tropinone and granatanone. At the B3LYP/6$311++g(3 d, 3 p)$ level, zwitterions were higher by 7.2 and $10.7 \mathrm{kcal} / \mathrm{mol}$ (Table 4 ). The dimer of enolate and protonated tropinone was even less stable than the zwitterion: in the gasphase 44.7 and in water $26.0 \mathrm{kcal} / \mathrm{mol}$ above the enol form at the B3LYP/6-31g(d) level. According to our calculations in water, the hydrated zwitterionic forms (10 and 11, Figure 6) have higher energies compared to nonhydrated species (7 and 8 ) by ca. 3 and ca. $6 \mathrm{kcal} / \mathrm{mol}$ at the B3LYP/6-31g(d) and B3LYP/6-311++g(3d,3p) levels, respectively. Thus, such enolate species, although imaginable, are highly unlikely to play a significant role in these reactions, which are run in an aqueous environment.

Calculated at the $6-311++\mathrm{g}(3 \mathrm{~d}, 3 \mathrm{p})$ level of theory, free energy differences between ketone and enol forms (Figure 6, predominating $\mathrm{N}$-invertomers shown) suggest that, in water, granatanone should have a higher enol form contribution than tropinone (Table 4). Both tropinone (1) and granatanone (2) should exhibit a higher percentage of the enol forms (lower $\Delta G$ of enolization) than typical ketones, for example, cyclohexanone $\left(7.36 \mathrm{kcal} / \mathrm{mol}\right.$ and $\mathrm{pK}_{\text {enol }}=5.4$ [49]) or acetone $\left(9 \mathrm{kcal} / \mathrm{mol}\right.$ [26] or $11.2 \mathrm{kcal} / \mathrm{mol}$ and $\mathrm{pK}_{\text {enol }}=8.22$ [50]). The result at 6-31g(d) level suggests also a higher degree of enolization for granatanone (2) than for tropinone (1), thus properly reproducing the higher level results (Table 4). With this method, the free energies of enolization for $\mathbf{1}$ and 
TABLE 1: Distributions of the products of the aldol reaction of tropinone and granatanone with benzaldehyde at $25^{\circ} \mathrm{C}$ calculated with different methods.

\begin{tabular}{|c|c|c|c|c|c|c|c|}
\hline \multirow[b]{2}{*}{ Method [lit. ref.] } & \multirow[b]{2}{*}{$\begin{array}{l}\text { Reaction } \\
\text { medium }\end{array}$} & \multicolumn{3}{|c|}{$\begin{array}{l}\text { Tropinone (exp. dr }{ }^{\mathrm{a}} \text { neat } 10: 90 \text {, water } \\
41: 59)\end{array}$} & \multicolumn{3}{|c|}{ Granatanone (exp. dra neat $11: 89$, water $39: 61$ ) } \\
\hline & & $\begin{array}{l}\text { Calculated } \\
\mathrm{dr}^{\mathrm{b}} \text { anti:syn }\end{array}$ & $\begin{array}{l}\text { Deviation of } \\
\text { calculated } \\
\text { from } \\
\text { experimental } \\
\mathrm{dr}^{\mathrm{c}}[\%]\end{array}$ & MAD & $\begin{array}{l}\text { Calculated } \\
\mathrm{dr}^{\mathrm{b}} \text { anti:syn }\end{array}$ & $\begin{array}{l}\text { Deviation of } \\
\text { calculated } \\
\text { from } \\
\text { experimental } \\
\mathrm{dr}^{\mathrm{c}}[\%]\end{array}$ & MAD \\
\hline \multirow[t]{2}{*}{ M062X/6-3lg(d) } & Gas/neat & $3: 97$ & 72 & \multirow{2}{*}{70} & $5: 95$ & 57 & \multirow{2}{*}{46.5} \\
\hline & Water & $18: 82$ & 68 & & $29: 71$ & 36 & \\
\hline \multirow{2}{*}{ BH\&HLYP/6-3lg(d) } & Gas/neat & $11: 89$ & 11 & \multirow{2}{*}{20} & $10: 90$ & 10 & \multirow{2}{*}{9} \\
\hline & Water & $33: 67$ & 29 & & $37: 63$ & 8 & \\
\hline \multirow{2}{*}{ B3LYP/6-31G(d) } & Gas/neat & $11: 89$ & 11 & \multirow{2}{*}{5.5} & $11: 89$ & 0 & \multirow{2}{*}{2} \\
\hline & Water & $41: 59$ & 0 & & $38: 62$ & 4 & \\
\hline \multirow[t]{2}{*}{ B3LYP/6-31G(d,p) } & Gas/neat & $10: 90$ & 0 & \multirow{2}{*}{9.5} & $9: 91$ & 20 & \multirow[t]{2}{*}{18} \\
\hline & Water & $36: 64$ & 19 & & $35: 65$ & 16 & \\
\hline \multirow{2}{*}{ B3LYP/6-311++G(3d,3p) } & Gas/neat & $17: 83$ & 84 & \multirow{2}{*}{56} & $16: 84$ & 54 & \multirow{2}{*}{33} \\
\hline & Water & $47: 53$ & 28 & & $36: 64$ & 12 & \\
\hline \multirow{2}{*}{ BH\&HLYP/cc-pVDZ } & Gas/neat & $11: 89$ & 11 & \multirow{2}{*}{17} & $9: 91$ & 20 & \multirow{2}{*}{12} \\
\hline & Water & $35: 65$ & 23 & & $40: 60$ & 4 & \\
\hline
\end{tabular}

${ }^{a}$ Diastereoisomer ratio of anti to syn isomers as indicated by NMR analysis. ${ }^{b}$ Diastereoisomer ratio given as a ratio of the sum of both anti forms (HB-O, HB$\mathrm{N})$ to both syn forms (HB-O, HB-N). ${ }^{c}$ Calculated as $100 \% \cdot\left|\mathrm{dr}_{\text {expt }}-\mathrm{dr}_{\text {calcd }}\right| / \mathrm{dr}_{\text {expt }}$. MAD: mean average deviations to experimental results.

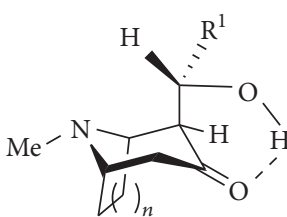

exo, anti HB-O

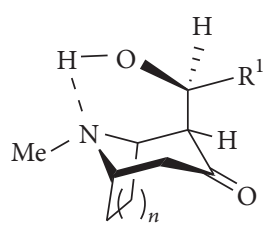

exo, anti $\mathrm{HB}-\mathrm{N}$

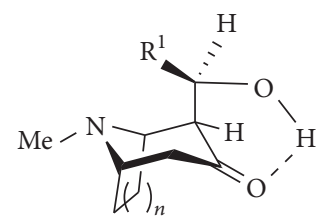

exo, syn $\mathrm{HB}-\mathrm{O}$

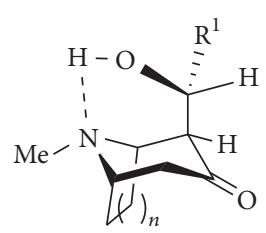

exo, syn $\mathrm{HB}-\mathrm{N}$
FIGURE 3: Structures of the main H-bond stabilized conformers of the diastereoisomeric aldols of tropinone and granatanone.

$\mathbf{2}$ are estimated in the range found experimentally for cyclohexanone [49]. Bearing in mind the possibility of hydration of tropinone and granatanone we asked how a hydration, similar to that, observed by us in crystal of granatanone, may affect the $\Delta G$ of enolization. Calculations showed that the free energies of enolization for $\mathbf{1}$ and $\mathbf{2}$ are lowered, if one considers the $\beta$-amino ketones hydrated by a molecule of water (Table 4). This tendency is especially noticeable in water (in aqueous solution). For example, the difference in the $\Delta G$ of enolization of axial $\mathrm{N}$-invertomers of granatanone with and without one molecule of water is $2.1 \mathrm{kcal} / \mathrm{mol}$ (Table 4 ). However, the supposedly more accurate calculations with $6-311++g(3 d, 3 p)$ basis set did not reproduce lowering of enolization energy with an explicit water molecule placed close to the oxygen atom of the enolate and ketone (Table 4). Placement of explicit $\mathrm{H}_{2} \mathrm{O}$ molecule bond to $\mathrm{N}$ atom resulted in higher enolization energy than enolization energy of species with $\mathrm{H}_{2} \mathrm{O}$ bound to oxygen by ca. $1 \mathrm{kcal} / \mathrm{mol}$ for B3LYP/6-31g(d) theory level.

Since the lower level results properly predict disparity in enolization of $\mathbf{2}$ and $\mathbf{1}$, which should be expected on grounds of differences in the bicyclic structures (the steric interactions of the carbonyl group and the C-7 atom in $\mathbf{2}$ versus the C6-C7 bridge in 1), they are likely more accurate in this case. This further confirms our using the B3LYP/6$3 \lg (\mathrm{d})$ as the method of choice. Based on chemical intuition and inspection of models one could expect that the relief of the steric congestion (Figure 6) may stabilize the flattened structure of granatanone enol (6) more than that of tropinone (5), compared to the parent ketone. The difference in the $\Delta G$ of enolization could also account for different rate of protiumdeuterium exchange (exchange of the axial hydrogens in the $\alpha$-position in granatanone is faster (ca. 90\% exchange for deuterium in $2 \mathrm{~h}$ ), then in tropinone (ca. $70 \%$ deuteration in $2 \mathrm{~h}$ ) as observed by ${ }^{1} \mathrm{H}-\mathrm{NMR}$ spectroscopy). Computations of the free energy of enolization that are more relevant to our reaction, that is, for ketones associated with benzaldehyde molecule in water using B3LYP/6-31g(d) CPCM method, provided smaller values: 5.9 for tropinone and $4.3 \mathrm{kcal} / \mathrm{mol}$ for granatanone [24]. The respective values for the gas-phase enolization were 6.2 and $4.6 \mathrm{kcal} / \mathrm{mol}$. Thus, assuming the prior enolization step in the presence of water or benzaldehyde (with $\Delta G$ ca. $4.3-6.2 \mathrm{kcal} / \mathrm{mol}$; see Table 4 ), we were in a position to explore the key step-the addition of the enol 


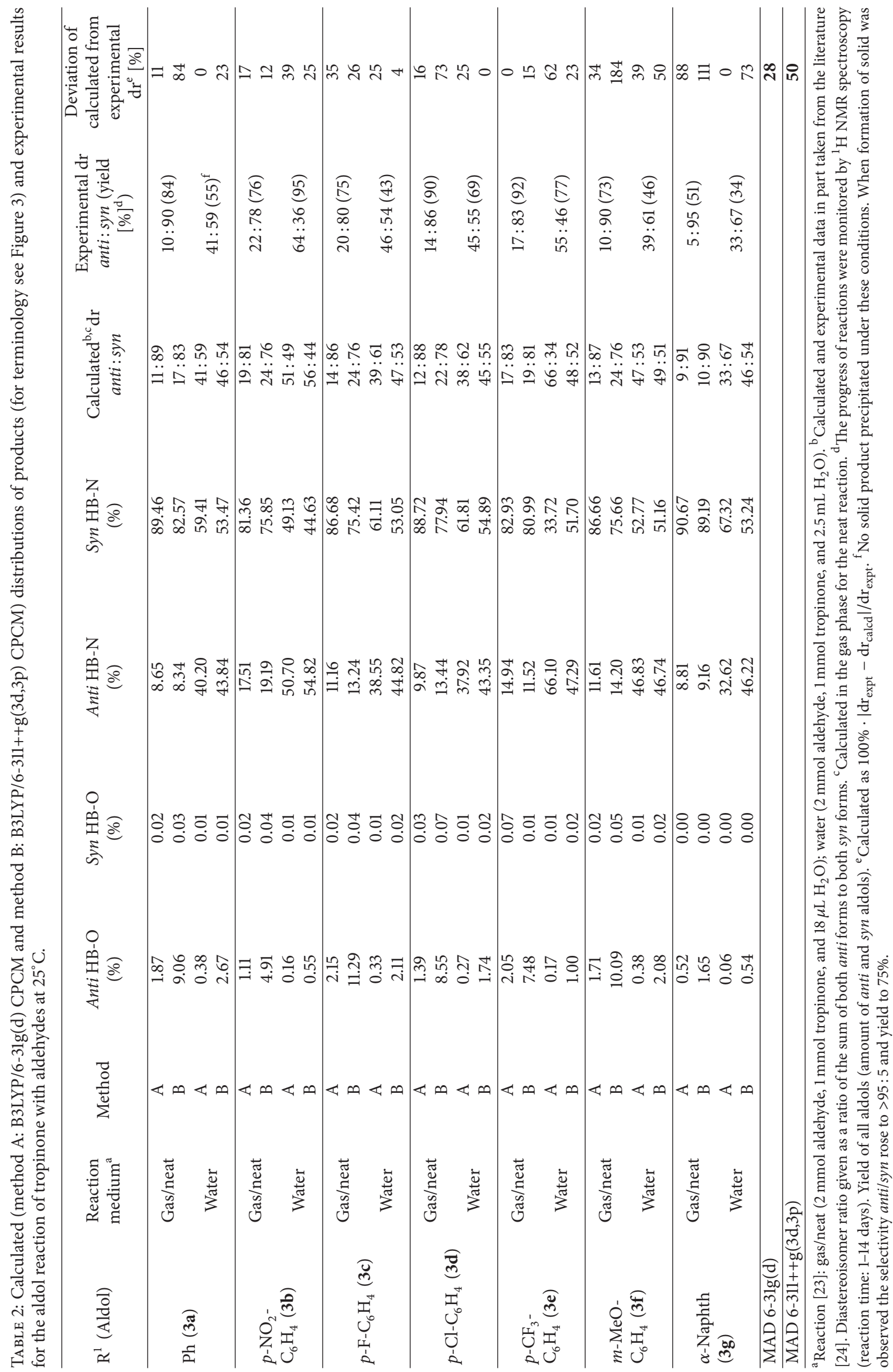




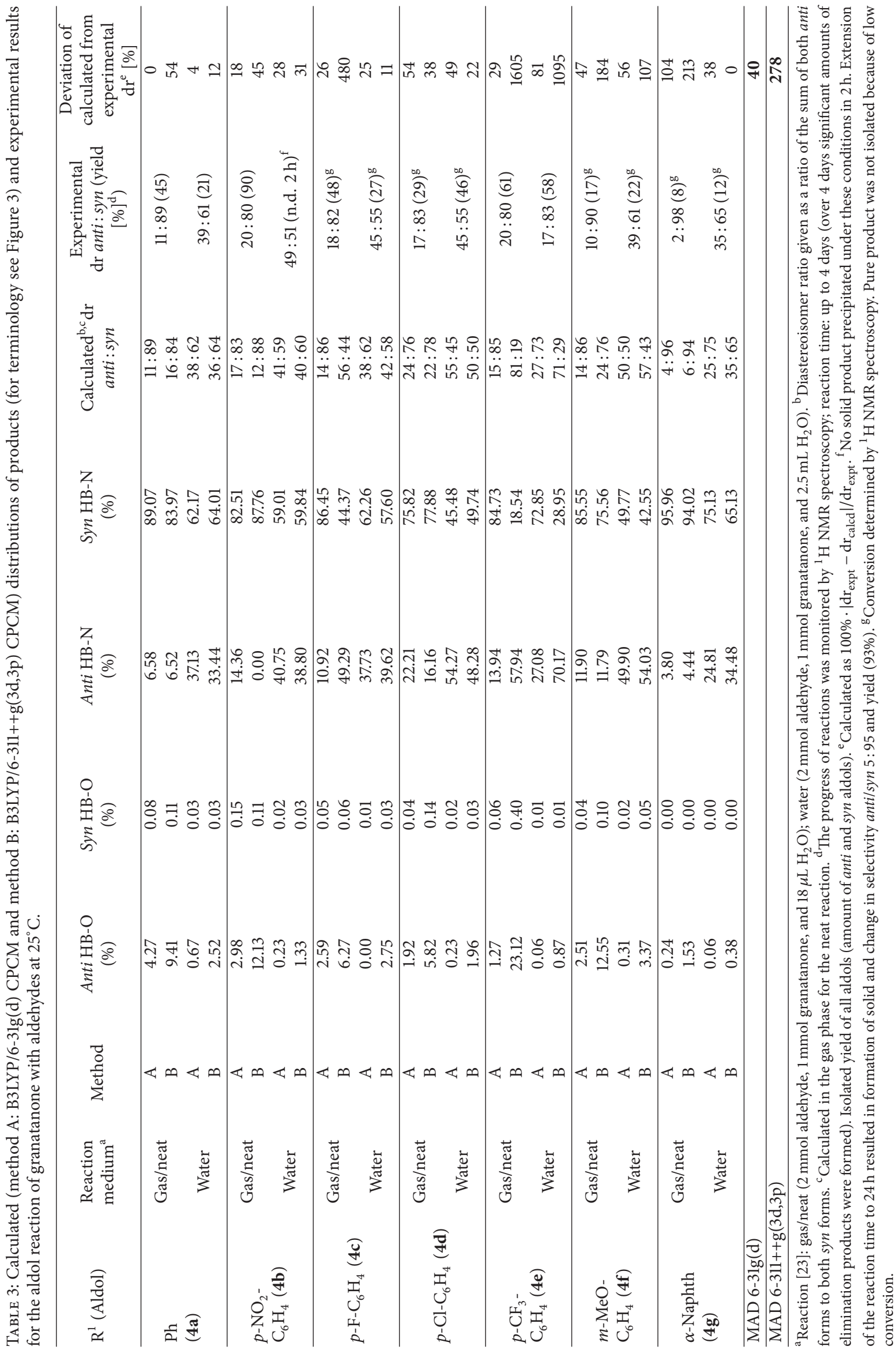




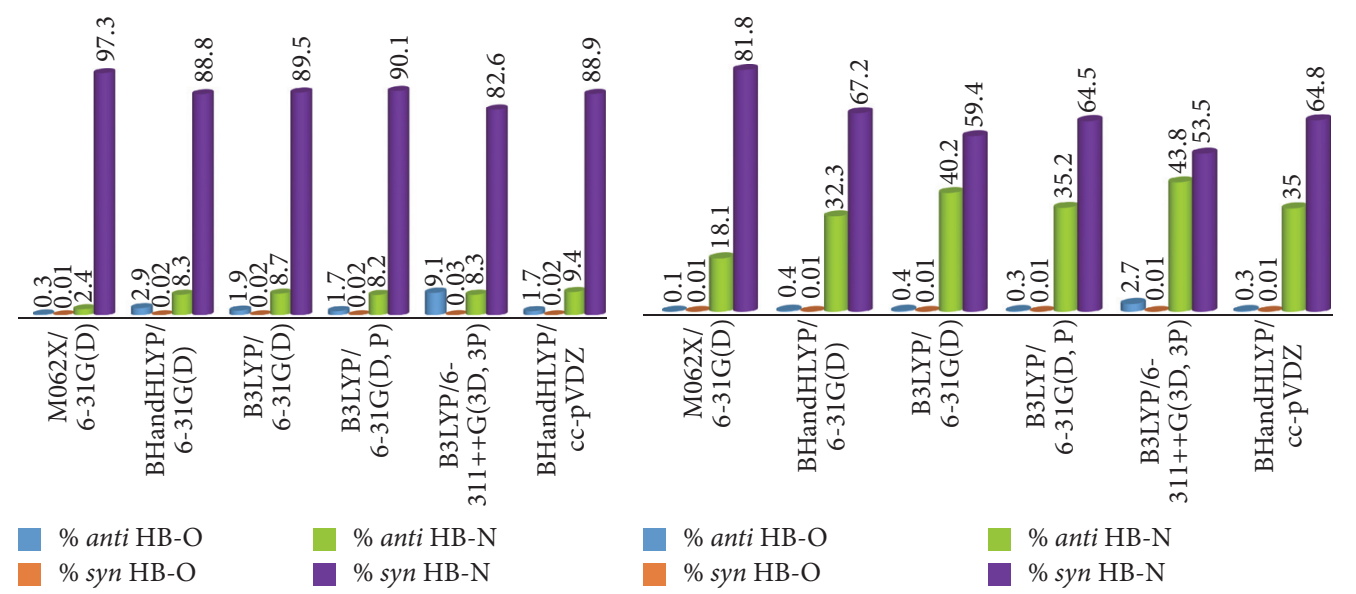

(a) Calculated distribution of tropinone aldol (neat/ gas)

(b) Calculated distribution of tropinone aldol (water)

FIGURE 4: Calculated distributions of tropinone aldol 3a (with benzaldehyde) forms for gas/neat reaction (a) and for reaction in water (b). Charts prepared with numerical data from Table 1.

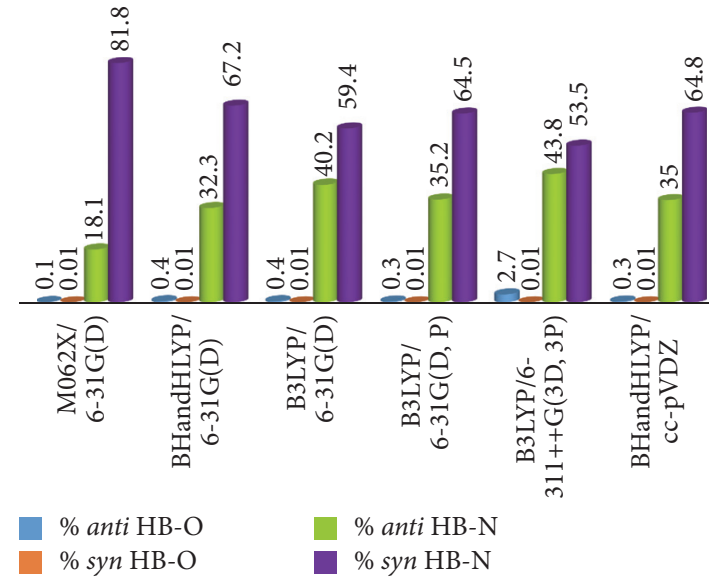

(a) Calculated distribution of granatanone aldol (neat/gas)

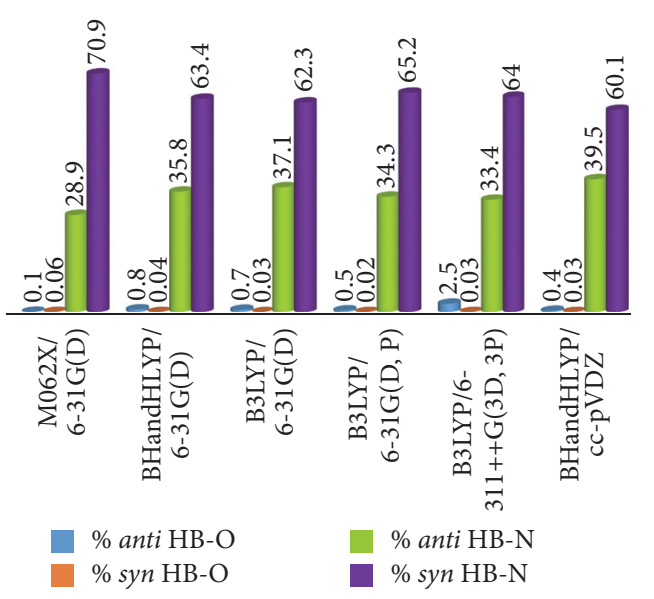

(b) Calculated distribution of granatanone aldol (water)

FIGURE 5: Calculated distributions of granatanone aldol 4a (with benzaldehyde) forms for gas/neat reaction (a) and for reaction in water (b). Charts prepared with numerical data from Table 1.

to an aldehyde-and possibly rationalize the outcome of the whole aldol process.

At first glance, the reaction parameters obtained from our computational approach, at 6-31g(d) level (but also at 6$311++\mathrm{g}(3 \mathrm{~d}, 3 \mathrm{p})$ vide infra $)$, calculated along the lines used for aldol reaction of acetone by Zhang and Houk [26], that is, the reaction of tropinone and granatanone enols with benzaldehyde, totally disagreed with experiment. Representative (for benzaldehyde) energy versus reaction coordinate (IRC) plots is shown in Figure 7.

The free energies obtained (Figure 7, Tables 5 and 6) for the hydrogen bond stabilized conformer of the addition product (marked HB-O, Figure 3) did not show any relationship to the experimental observations; the experimentally observed selectivity disagreed qualitatively with both the kinetic and the thermodynamic parameters calculated for the reactions.
According to these calculations in all reactions (Tables 5 and 6) the exo,anti-product should be favoured both kinetically $[\mathrm{k}($ anti)/k(syn)] and thermodynamically (Kanti/syn for HB$\mathrm{O})$. As can be seen in Figures 3 and 7, the initially formed HB-O form may undergo conformational change forming another stable structure with hydrogen bond to the nitrogen atom (marked HB-N conformer, Figure 3). The HB-N form does not result directly from the aldol addition but is stabilized by formation of a hydrogen bond to the tertiary nitrogen atom. Structures with such internal hydrogen bond have been observed for this type of aldols in crystals $[18,22$, 51-53].

In a preliminary report we showed that the neat/solventless reaction conditions were most accurately reproduced by the gas-phase DFT calculations which integrated such (HBN) structures [24]. As can be seen in Tables 5 and 6, for 


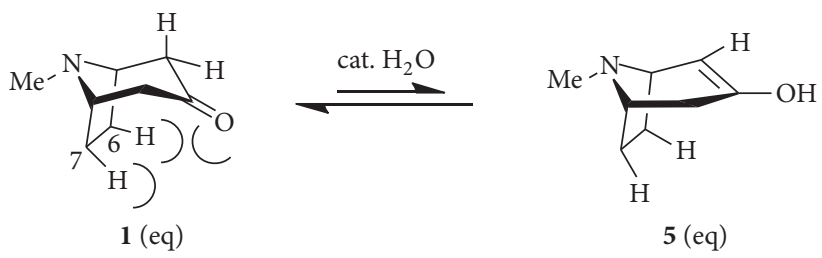

B3LYP/6-31g(d): 1 (eq) to 5 (eq): $\Delta G\left(\mathrm{H}_{2} \mathrm{O}\right)=7.4 \mathrm{kcal} / \mathrm{mol}$
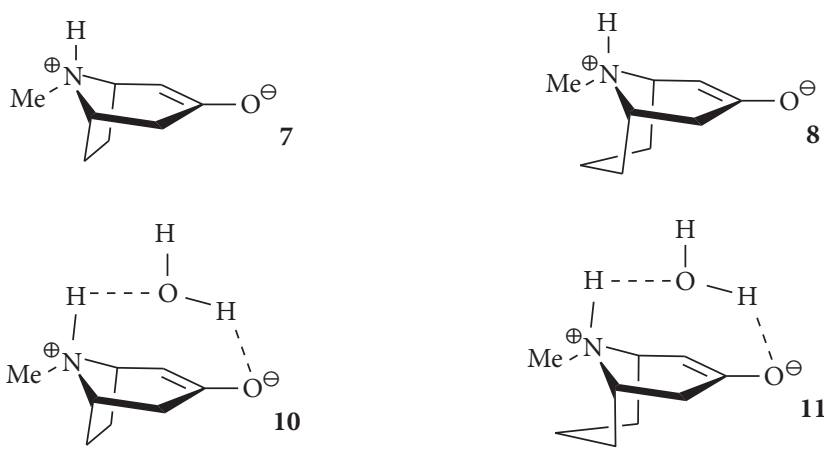
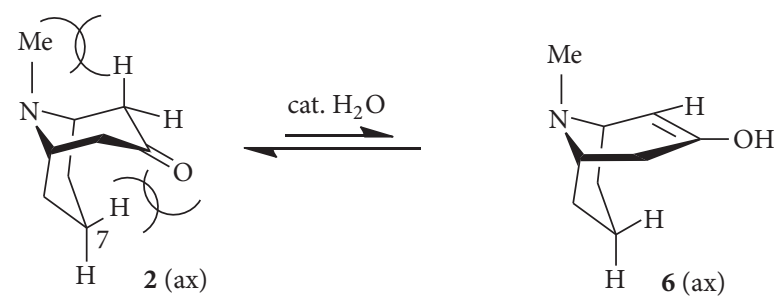

B3LYP/6-31g(d): $2(\mathrm{ax})$ to $6(\mathrm{ax}): \Delta G\left(\mathrm{H}_{2} \mathrm{O}\right)=5.2 \mathrm{kcal} / \mathrm{mol}$
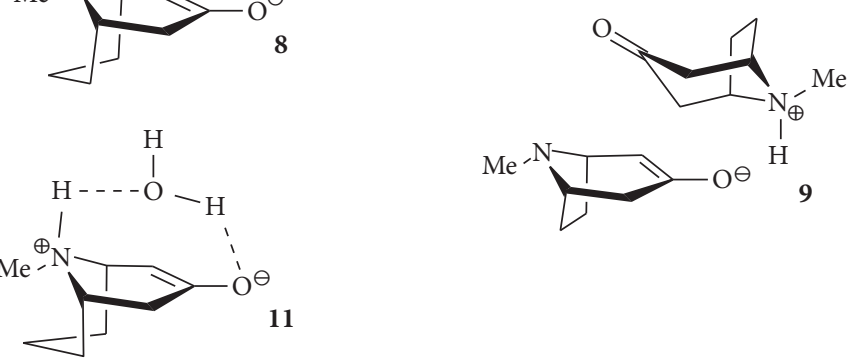

FIGURE 6: Considered possible forms of reacting donor species and steric interaction relieved during enolization of tropinone and granatanone (numerical data from Table 4).

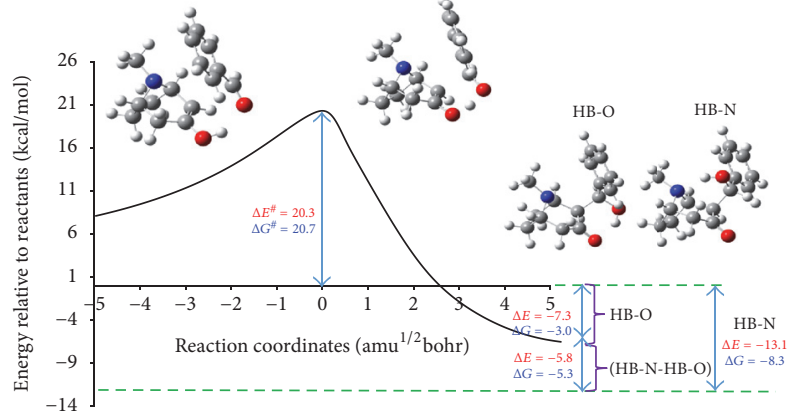

(a)

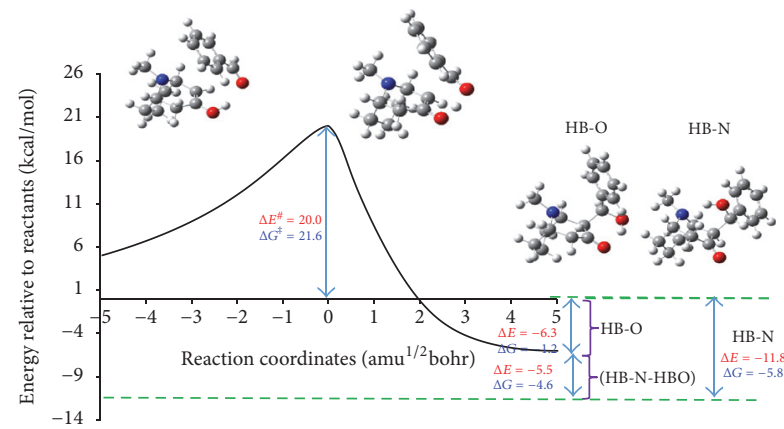

(c)

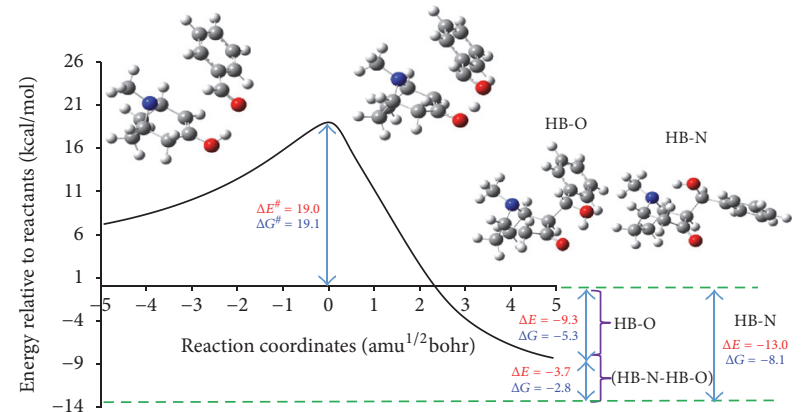

(b)

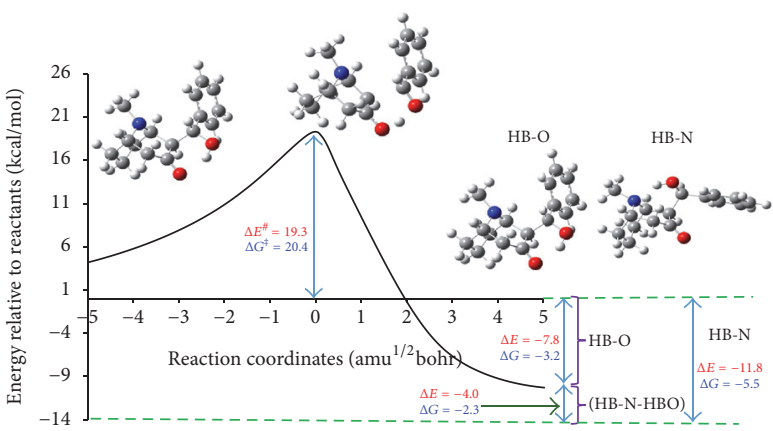

(d)

Figure 7: The classical adiabatic ground state $\left(V_{C}\right)$ potential energy curve along the reaction coordinates of the aldol addition of tropinone enol (a, b) and granatanone enol (c, d) to benzaldehyde proceeding to the exo,syn (a, c) and the exo, anti $(\mathrm{b}, \mathrm{d})$ isomers. The activation energies $\left(E_{\mathrm{TS}}-E_{\text {reactants }}\right)$, reaction energies $\left(E_{\text {product }}-E_{\text {reactants }}\right)$, and differences of energies $(\Delta E)$ of the HB-N and HB-O forms of the isomeric products are shown in red. For the sake of comparison, the corresponding free energies differences $(\Delta G)$ are given in blue. Note that the ordinates correspond to the energies $(E)$ not free energies $(G)$, so the blue values cannot be figured out from the chart. 
TABLE 4: Free energies of enolization of tropinone and granatanone computed at the B3LYP/6-31g(d) and B3LYP/6-311++g(3d,3p) (in parenthesis, italics) levels.

\begin{tabular}{|c|c|c|c|c|c|c|c|c|}
\hline \multicolumn{9}{|c|}{$\Delta G$ of enolization $\left(G_{\text {enol }}-G_{\text {ketone }}\right)$} \\
\hline \multirow[t]{2}{*}{ Ketone } & \multirow{2}{*}{$\begin{array}{l}\text { Reaction } \\
\text { medium }\end{array}$} & \multicolumn{2}{|c|}{$\begin{array}{l}\text { Without explicit } \\
\qquad \mathrm{H}_{2} \mathrm{O}\end{array}$} & \multicolumn{2}{|c|}{$\begin{array}{l}\text { With explicit molecule } \\
\text { of } \mathrm{H}_{2} \mathrm{O}\end{array}$} & \multirow[t]{2}{*}{$\begin{array}{l}\text { Zwitterionic } \\
\text { form }\end{array}$} & $\begin{array}{l}\text { Hydrated } \\
\text { zwitteri- } \\
\text { onic } \\
\text { form }\end{array}$ & \multirow{2}{*}{$\begin{array}{c}\text { With } \\
\text { explicit } \\
\text { molecule } \\
\text { of } \mathrm{PhCHO} \\
{[24]} \\
\text { omer }\end{array}$} \\
\hline & & $\mathrm{ax}^{\mathrm{a}}$ & $\mathrm{eq}^{\mathrm{a}}$ & $\mathrm{ax}^{\mathrm{a}}$ & $\mathrm{eq}^{\mathrm{a}}$ & & table N-inv & \\
\hline \multirow{2}{*}{ Tropinone } & Gas & $\begin{array}{c}5.6 \\
(4.9)\end{array}$ & $\begin{array}{c}7.4 \\
(6.5)\end{array}$ & $\begin{array}{c}4.3 \\
(5.4)\end{array}$ & $\begin{array}{c}7.3 \\
(6.6)\end{array}$ & - & - & 6.2 \\
\hline & $\begin{array}{l}\text { Water } \\
\text { (CPCM) }\end{array}$ & $\begin{array}{c}6.4 \\
(6.2)\end{array}$ & $\begin{array}{c}7.4 \\
(7.2)\end{array}$ & $\begin{array}{c}4.7 \\
(6.8)\end{array}$ & $\begin{array}{c}6.0 \\
(7.5)\end{array}$ & $\begin{array}{c}18.6 \\
(14.4)\end{array}$ & $\begin{array}{c}21.7 \\
(20.2)\end{array}$ & 5.9 \\
\hline \multirow{2}{*}{ Granatanone } & Gas & $\begin{array}{c}4.7 \\
(3.5)\end{array}$ & $\begin{array}{c}6.2 \\
(5.4)\end{array}$ & $\begin{array}{l}4.5 \\
(4.1)\end{array}$ & $\begin{array}{c}6.2 \\
(7.6)\end{array}$ & - & - & 4.6 \\
\hline & $\begin{array}{l}\text { Water } \\
\text { (CPCM) }\end{array}$ & $\begin{array}{c}5.2 \\
(5.2)\end{array}$ & $\begin{array}{c}6.4 \\
(6.3)\end{array}$ & $\begin{array}{c}3.1 \\
(5.7)\end{array}$ & $\begin{array}{c}4.9 \\
(6.0)\end{array}$ & $\begin{array}{c}18.4 \\
(15.9)\end{array}$ & $\begin{array}{c}21.3 \\
(22.0)\end{array}$ & 4.3 \\
\hline
\end{tabular}

${ }^{\mathrm{a}} \mathrm{N}-\mathrm{Me}$ group position.

reactions taking place both in water and in the absence of solvent, there exists correspondence between the experimental ratio (dr) of exo,anti/exo,syn isomers $\left(\mathrm{dr}_{\exp }\right.$ anti/syn) and the equilibrium constant for the interconversion of the HB$\mathrm{N}$ conformers (Kanti/syn for HB-N) of these isomers. This correspondence combined with the observed equilibration suggests the thermodynamic control of the reaction and involvement of the interconversion of the competing product conformers in the equilibrium. Because of the bicyclic structure (endo and exo faces) of tropane and granatane derivatives, we propose that the syn-anti isomerization of the aldols takes place through retroaldolization (observed in several instances) $[19,22,54]$ and not by enolization mechanism reported, for example, in the imidazole catalysed isomerization $[55,56]$.

Assuming thermodynamic control, it is reasonable to expect that the experimentally observed dr's should result from weighted contributions of the forms involved in the equilibrium. Consequently, the question arises as to whether taking into account the contributions of the other, less stable, forms (the HB-O) would give even better agreement of theory with experiment. To test it, we converted free energies of formation of both ( $\mathrm{HB}-\mathrm{O}$ and $\mathrm{HB}-\mathrm{N}$ ) forms of competing diastereoisomers to percentage distribution.

Results calculated with two basis sets, 6-31g(d) and 6$311++g(3 d, 3 p)$, for tropinone and granatanone are presented in Tables 2 and 3, respectively. In these tables MAD (mean average deviations of the calculated and experimental dr's) for basis set $6-31 g(d)$ are smaller than the MAD in Tables 5 and 6 , where the other conformers were ignored, thus validating this approach. For several aldehydes (Tables 2 and $3, R_{1}$ $=\mathrm{Ph}, p-\mathrm{NO}_{2}-\mathrm{C}_{6} \mathrm{H}_{4}, p-\mathrm{F}-\mathrm{C}_{6} \mathrm{H}_{4}$, and $\left.p-\mathrm{CF}_{3}-\mathrm{C}_{6} \mathrm{H}_{4}\right)$ excellent agreement (deviation below 30\%) was found. Interestingly, the results obtained with the B3LYP/6-311++g(3d,3p) showed, in general, worse agreement with experiment. However, it must be noted that in some instances this high-end and more computationally demanding basis set gave slightly better agreement with experiment (e.g., $p-\mathrm{F}-\mathrm{C}_{6} \mathrm{H}_{4}, p-\mathrm{Cl}-\mathrm{C}_{6} \mathrm{H}_{4}$, and
$\alpha$-Napht), but no clear rules with regard to neither medium nor reactant may be drawn here. The calculated $\Delta G$ values for the HB-O and HB-N forms (Tables 5 and 6) can also explain observed low conversions and, consequently, low yields (or failed isolation of products in extreme cases). In theory, given sufficient reaction rate, sum of the free energies of formation of the HB-O or the HB-N forms of products and $\Delta G$ of enolization for the ketone used could be used to determine conversion of the reaction for particular reactants.

Indeed, the calculated $\Delta G$ 's for the HB-O and the HB-N isomers are somehow related to the conversions and yields found experimentally (compare Tables 2 and 3 with Tables 5 and 6). Assuming the enolization free energy for tropinone and granatanone ca. 5.9 and $4.3 \mathrm{kcal} / \mathrm{mol}$, respectively, the calculated $\Delta G$ 's predicted poor results found later on with some aldehydes (e.g., products $\mathbf{3 h}, \mathbf{4 g}$, and $\mathbf{4 h}$ ). Experimentally, several of the granatanone reactions gave poor outcome. In general, reactions with granatanone gave lower yields (or showed lower conversion) than those with tropinone. This was expected based on calculated lower thermodynamic drive for the addition step of the granatanone enol (average $\Delta G-2.8$ for the HB-O and $-6.2 \mathrm{kcal} / \mathrm{mol}$ for the HB-N) than for the tropinone enol (average $\Delta G-4.1$ for the $\mathrm{HB}-\mathrm{O}$ and $-7.8 \mathrm{kcal} / \mathrm{mol}$ for the HB-N). Calculations for reactions of some aldehydes, for example, $\alpha$-naphthaldehyde and notably $p$-methoxybenzaldehyde, gave very small (as compared to the estimated $\Delta G$ for the ketones enolization, that is, 4.3$6.2 \mathrm{kcal} / \mathrm{mol}$ ) negative or even positive $\Delta G$ values (Tables 5 and $6,3 \mathbf{h}, \mathbf{4 g}$, and $\mathbf{4 h}$ ). In all such cases experiments confirmed correctness of the prediction and showed low conversions. Expansion of aldehyde range in this work to include $p$-methoxybenzaldehyde gave result so poor that neither conversion nor isomers ratio could be measured (n.d. in Tables 5 and 6). This failure was predicted based on calculations. Because rotation of $\mathrm{C}-\mathrm{C}$ bond and formation of the HB-N form follow formation of the HB-O product, the positive or not sufficiently negative $\Delta G$ for formation of the initial addition product-the $\mathrm{HB}-\mathrm{O}$ form-hinders the 
TABLE 5: Calculated (B3LYP/6-31g(d) CPCM) reaction parameters for tropinone enol addition to aldehydes.

\begin{tabular}{|c|c|c|c|c|c|c|c|c|c|}
\hline $\mathrm{R}^{1}$ & $\begin{array}{l}\text { Reaction } \\
\text { medium }\end{array}$ & Aldol isomer & $\begin{array}{c}\Delta G^{\neq} \\
\mathrm{HB}-\mathrm{O}\end{array}$ & $\mathrm{k}($ anti)/ $\mathrm{k}($ syn $)$ & $\begin{array}{c}\Delta G \\
\mathrm{HB}-\mathrm{O}\end{array}$ & $\begin{array}{c}\mathrm{K} \\
\text { anti/syn } \\
\mathrm{HB}-\mathrm{O}\end{array}$ & $\begin{array}{c}\Delta G \\
\mathrm{HB}-\mathrm{N}\end{array}$ & $\begin{array}{c}\mathrm{K} \text { anti/syn } \\
\mathrm{HB}-\mathrm{N}\end{array}$ & $\begin{array}{c}\mathrm{dr}_{\exp } \\
\text { anti/syn }\end{array}$ \\
\hline \multirow{4}{*}{$\mathrm{Ph}$} & \multirow{2}{*}{ Gas/neat } & exo,syn-3a & 20.1 & \multirow{2}{*}{41.3} & -2.0 & \multirow{2}{*}{133.9} & -7.2 & \multirow{2}{*}{0.1} & \multirow{2}{*}{0.11} \\
\hline & & exo,anti-3a & 18.9 & & -4.9 & & -5.8 & & \\
\hline & \multirow{2}{*}{ Water } & exo,syn-3a & 20.7 & \multirow{2}{*}{15.2} & -3.0 & \multirow{2}{*}{48.6} & -8.3 & \multirow[t]{2}{*}{0.7} & \multirow{2}{*}{0.69} \\
\hline & & exo,anti-3a & 19.1 & & -5.3 & & -8.1 & & \\
\hline \multirow{4}{*}{$p-\mathrm{NO}_{2}-\mathrm{C}_{6} \mathrm{H}_{4}$} & \multirow{2}{*}{ Gas/net } & exo,syn-3b & 17.8 & \multirow{2}{*}{14.4} & -6.1 & \multirow{2}{*}{48.6} & -10.9 & \multirow{2}{*}{0.2} & \multirow{2}{*}{0.28} \\
\hline & & exo,anti-3b & 16.2 & & -8.4 & & -10.0 & & \\
\hline & \multirow{2}{*}{ Water } & exo,syn-3b & 18.2 & \multirow{2}{*}{6.1} & -6.5 & \multirow{2}{*}{29.3} & -11.9 & \multirow{2}{*}{1.0} & \multirow{2}{*}{1.78} \\
\hline & & exo,anti-3b & 17.1 & & -8.5 & & -11.9 & & \\
\hline \multirow{4}{*}{$p-\mathrm{F}-\mathrm{C}_{6} \mathrm{H}_{4}$} & \multirow{2}{*}{ Gas/neat } & exo,syn-3c & 21.3 & \multirow{2}{*}{31.3} & -1.7 & \multirow{2}{*}{113.1} & -6.7 & \multirow{2}{*}{0.1} & 0.25 \\
\hline & & exo,anti-3c & 19.3 & & -4.5 & & -5.5 & & 0.25 \\
\hline & Water & exo,syn-3c & 21.7 & 14.9 & -2.0 & 48.6 & -7.4 & & \\
\hline & Water & exo,anti-3c & 20.1 & 14.9 & -4.3 & 48.6 & -7.1 & 0.6 & 0.85 \\
\hline & Gas/neat & exo,syn-3d & 20.1 & 21.3 & -3.3 & 48.6 & -8.1 & 0.1 & 0.16 \\
\hline$p-\mathrm{Cl}-\mathrm{C}_{6} \mathrm{H}_{4}$ & & exo,anti-3d & 18.3 & 21.3 & -5.6 & 48.0 & -6.8 & 0.1 & 0.10 \\
\hline$P-\mathrm{P}_{6} \mathrm{C}_{4}$ & Water & exo,syn-3d & 21.4 & 14.9 & -2.8 & 41.1 & -8.2 & 0.6 & 0.82 \\
\hline & vrater & exo,anti-3d & 19.8 & 14. & -5.0 & 11.1 & -7.9 & 0.0 & 0.02 \\
\hline & & exo,syn-3e & 18.9 & & -5.1 & & -9.3 & & \\
\hline$p-\mathrm{CF}_{2}-\mathrm{C}_{6} \mathrm{H}_{4}$ & Gas/neat & exo,anti-3e & 16.7 & 40.2 & -7.1 & 29.3 & -8.3 & 0.2 & 0.20 \\
\hline $6^{11_{4}}$ & & exo,syn-3e & 20.4 & & -4.2 & & -9.3 & & \\
\hline & Water & exo,anti-3e & 18.2 & 45.1 & -6.1 & 24.1 & -9.6 & 1.7 & 1.22 \\
\hline & Gas/neat & exo,syn-3f & 20.3 & 46.2 & -3.0 & 95.5 & -8.0 & 0.1 & 0.11 \\
\hline$m-\mathrm{MeO}-\mathrm{C}_{6} \mathrm{H}_{4}$ & & exo,anti-3f & 18.1 & & -5.7 & & -6.8 & & \\
\hline$m-1 v(c)-6^{11} 4$ & Water & exo,syn-3f & 20.6 & 12.9 & -3.3 & 41.1 & -8.0 & 1.7 & 0.64 \\
\hline & vrater & exo,anti-3f & 19.1 & 12.9 & -5.5 & 11.1 & -8.3 & 1.7 & 0.04 \\
\hline & Gas/neat & exo,syn-3g & 21.4 & 38.2 & -1.0 & 311.5 & -7.4 & 0.1 & 0.05 \\
\hline$\alpha$-Naphth- & Gas/neat & exo,anti-3g & 19.2 & 38.2 & -4.4 & 311.5 & -6.0 & 0.1 & 0.05 \\
\hline u-1 appinti- & Water & exo,syn-3g & 21.8 & 8.3 & -1.2 & 80.7 & -7.9 & 0.5 & 0.49 \\
\hline & water & exo,anti-3g & 20.5 & 8.3 & -3.8 & 80.1 & -7.5 & 0.3 & 0.49 \\
\hline & Gas/neat & exo,syn-3h & 21.9 & 35.7 & -0.4 & 96.5 & -5.1 & 0.1 & n.d. \\
\hline$p-\mathrm{MeO}-\mathrm{C}_{6} \mathrm{H}_{4}$ & & exo,anti-3h & 19.8 & (3. & -3.1 & & -3.9 & 0.1 & 11.u. \\
\hline$P$-IVIC $-\mathrm{C}_{6} \mathrm{II}_{4}$ & Water & exo,syn-3h & 22.4 & 43.0 & -0.8 & 65.7 & -5.8 & 1.0 & n.d. \\
\hline & vider & exo,anti-3h & 20.2 & 45.0 & -3.3 & 03.1 & -5.8 & 1.0 & 11.u. \\
\hline $\mathrm{MAD} \mathrm{K}_{a n t i / s y n}$ & $\mathrm{HBN}$ & & & & & & & & \\
\hline
\end{tabular}

entire aldol process, as is evident from data (Table 6) and low yield for $\alpha$-naphthaldehyde and granatanone (Table 3). For the sake of prediction of the success of the reactions with other aldehydes one could accept that reactions with $\Delta G$ for the isomer HB-O ca. $-3 \mathrm{kcal} / \mathrm{mol}$ and for the $\mathrm{HB}-\mathrm{N}$ ca. $-6 \mathrm{kcal} / \mathrm{mol}$ are at the borderline of acceptable yields.

In effect, we found that considering free energies of four hydrogen bond stabilized forms of possible products (including the $\mathrm{HB}-\mathrm{O}$ and the $\mathrm{HB}-\mathrm{N}$ forms) gave especially good correlation with experimental results for solventless reaction and also for reactions "diluted" with water, unless formation of solid products was involved [24]. Thus, processes where solid product deposited from the reacting mixture were clearly controlled by other phenomena; selectivity and conversions did not parallel the calculations and prediction of reaction result under such conditions is not possible. With the caveat that precipitation will affect the reaction equilibrium, the reported correlations of theory and experiment are useful for assessing outcome of new reactions.

\section{Conclusions}

(i) Two crystal structures of granatanone and its hemihydrate $(2 \cdot(1 / 2) \mathrm{H} 2 \mathrm{O})$ have been experimentally determined by single crystal X-ray diffraction. The experiments showed domination of the $\mathrm{N}$-axial forms in the 
TABLE 6: Calculated (B3LYP/6-31g(d) CPCM) reaction parameters for granatanone enol addition to aldehydes.

\begin{tabular}{|c|c|c|c|c|c|c|c|c|c|}
\hline $\mathrm{R}^{1}$ & Reaction medium & Aldol isomer & $\begin{array}{c}\Delta G^{\neq} \\
\mathrm{HB}-\mathrm{O}\end{array}$ & $\mathrm{k}($ anti)/k(syn) & $\begin{array}{c}\Delta G \\
\mathrm{HB}-\mathrm{O}\end{array}$ & $\begin{array}{c}\mathrm{K} \text { anti/syn } \\
\mathrm{HB}-\mathrm{O}\end{array}$ & $\begin{array}{c}\Delta G \\
\mathrm{HB}-\mathrm{N}\end{array}$ & $\begin{array}{c}\mathrm{K} \text { anti/syn } \\
\text { HB-N }\end{array}$ & $\begin{array}{c}\mathrm{dr}_{\exp } \\
\text { anti/syn }\end{array}$ \\
\hline \multirow{4}{*}{$\mathrm{Ph}$} & \multirow{2}{*}{ Gas/neat } & exo,syn-4a & 21.0 & \multirow[t]{2}{*}{18.1} & -1.3 & \multirow[t]{2}{*}{56.8} & -5.5 & \multirow[t]{2}{*}{0.1} & \multirow[t]{2}{*}{0.12} \\
\hline & & exo,anti-4a & 19.3 & & -3.7 & & -4.0 & & \\
\hline & \multirow{2}{*}{ Water } & exo,syn-4a & 21.6 & \multirow{2}{*}{7.5} & -1.2 & \multirow[t]{2}{*}{26.6} & -5.8 & \multirow[t]{2}{*}{0.6} & \multirow{2}{*}{0.64} \\
\hline & & exo,anti-4a & 20.4 & & -3.2 & & -5.5 & & \\
\hline \multirow{4}{*}{$p-\mathrm{NO}_{2}-\mathrm{C}_{6} \mathrm{H}_{4}$} & \multirow{2}{*}{ Gas/neat } & exo,syn-4b & 18.1 & \multirow{2}{*}{5.3} & -5.2 & \multirow{2}{*}{20.2} & -9.0 & \multirow[t]{2}{*}{0.2} & \multirow{2}{*}{0.25} \\
\hline & & exo,anti-4b & 17.1 & & -7.0 & & -7.9 & & \\
\hline & \multirow{2}{*}{ Water } & exo,syn-4b & 18.3 & \multirow{2}{*}{3.0} & -5.5 & \multirow{2}{*}{10.6} & -10.2 & \multirow{2}{*}{0.7} & \multirow{2}{*}{0.96} \\
\hline & & exo,anti-4b & 17.7 & & -6.9 & & -10.0 & & \\
\hline \multirow{4}{*}{$p-\mathrm{F}-\mathrm{C}_{6} \mathrm{H}_{4}$} & \multirow{2}{*}{ Gas/neat } & exo,syn-4c & 20.8 & \multirow{2}{*}{20.3} & -0.9 & \multirow{2}{*}{49.7} & -5.3 & \multirow{2}{*}{0.1} & 0.22 \\
\hline & & exo,anti-4c & 19.0 & & -3.3 & & -4.1 & & 0.22 \\
\hline & Water & exo,syn-4c & 20.9 & 68 & -1.5 & 317 & -6.5 & 06 & 082 \\
\hline & Water & exo,anti-4c & 19.8 & 6.8 & -3.6 & 31.7 & -6.2 & 0.6 & 0.82 \\
\hline & Gas/neat & exo,syn-4d & 19.9 & 10.4 & -2.1 & 488 & -6.6 & 0.3 & 0.20 \\
\hline$p-\mathrm{Cl}_{-} \mathrm{C}_{6} \mathrm{H}_{4}$ & & exo,anti-4d & 18.5 & & -4.4 & & -5.9 & & \\
\hline & Water & exo,syn-4d & 20.5 & 07 & -2.5 & 152 & -7.2 & 12 & 082 \\
\hline & & exo,anti-4d & 20.7 & & -4.1 & & -7.3 & & \\
\hline & Gas/neat & exo,syn-4e & 18.9 & 47 & -3.4 & 200 & -7.6 & 0.2 & 0.25 \\
\hline$p-\mathrm{CF}_{2}-\mathrm{C}_{6} \mathrm{H}_{2}$ & Gas/neat & exo,anti-4e & 18.0 & 4.7 & -5.1 & 20.0 & -6.6 & 0.2 & 0.25 \\
\hline$p-\mathrm{CF}_{3}-\mathrm{C}_{6} \mathrm{H}_{4}$ & Water & exo,syn-4e & 19.3 & 28 & -3.6 & 114 & -9.2 & 04 & 020 \\
\hline & Water & exo,anti-4e & 18.6 & 2.8 & -5.0 & 11.4 & -8.6 & 0.4 & 0.20 \\
\hline & Gas/neat & exo,syn-4f & 20.8 & 183 & -1.3 & 614 & -5.9 & 01 & 0.11 \\
\hline$m-\mathrm{MeO}-$ & & exo,anti-4f & 19.1 & & -3.8 & & -4.7 & & \\
\hline $\mathrm{C}_{6} \mathrm{H}_{4}$ & Water & exo,syn-4f & 21.1 & 6.4 & -1.8 & 146 & -6.4 & 10 & 0.64 \\
\hline & & exo,anti-4f & 20.0 & & -3.4 & & -6.4 & & \\
\hline & Gas/neat & exo,syn-4g & 21.9 & 142 & 0.8 & 1356 & -5.7 & 0.04 & 002 \\
\hline$\alpha$-Naphth- & Gas/neat & exo,anti-4g & 20.3 & 14.2 & -2.1 & 135.6 & -3.8 & 0.04 & 0.02 \\
\hline$\alpha$-Napnth- & Water & exo,syn-4g & 21.1 & 34 & -0.4 & 821 & -7.2 & 03 & 054 \\
\hline & Water & exo,anti-4g & 20.4 & 3.4 & -3.0 & 82.1 & -6.6 & 0.3 & 0.54 \\
\hline & Gas/neat & exo,syn-4h & 22.2 & 257 & 0.8 & 473 & -3.4 & 03 & $n d$ \\
\hline$p$-MeO-C $\mathrm{H}_{2}$ & & exo,anti-4h & 20.3 & 25.7 & -1.5 & & -2.7 & & \\
\hline & Water & exo,syn-4h & 22.6 & 14.5 & 0.4 & 26.2 & -3.9 & 1.5 & n.d. \\
\hline & & exo,anti-4h & 21.0 & & -1.5 & & -4.2 & & \\
\hline MAD K $\mathrm{K}_{\text {anti/syn }}$ & $\mathrm{HBN}$ & & & & & & & & \\
\hline
\end{tabular}

solid state and hydration of the nitrogen site of two granatanone molecules.

(ii) Despite the fairly expanded scope of tested computational methods, including a recently introduced functional (M062X), the B3LYP/6-31g(d) accounting for the orbital relaxation upon immersion in solution (i.e., geometry optimization in liquid state performed with CPCM) is still recommended as the most accurate and additionally cost effective approach, to probe reactivity and selectivity in this specific type of aldol reactions.

(iii) Presence of basic nitrogen in substrates results in considerable concentration of strong specific base in their aqueous solutions ( $\mathrm{pH}$ ca. 10). Considering the most stable forms of hydrated $\beta$-amino ketones, our computations indicated lowering of the free energies of enolization, suggesting higher equilibrium concentration of the enol forms in the presence of water. This may be another factor responsible for the beneficial role of water in the process.

(iv) For the studied range of aldehydes the diastereoselectivities and conversions of the aldol reactions can be computationally reproduced (the exo,syn isomers are typically the most stable forms and dominate in the solventless reaction) and even predicted (no product with $p$-methoxybenzaldehyde).

(v) Yield of the particular reaction can be correlated with the calculated free energies of formation of the 
$\mathrm{HB}-\mathrm{O}$ and the HB-N forms of products and $\Delta G$ of enolization for the ketone used.

(vi) The experimental observation that tropinone gives in general better results than granatanone is reflected in calculated thermodynamic parameters $(\Delta G)$ for formation of products conformers stabilized by hydrogen bonding.

\section{Experimental Section}

9-Methyl-9-azabicyclo[3.3.1]nonan-3-one (2). Crystals suitable for X-ray diffraction study were obtained at $255 \mathrm{~K}$ from a mixture of $n$-hexane-ethyl ether (ratio 5:1) and molecular sieves $4 \AA$. The X-ray diffraction data were collected at $100(2) \mathrm{K}$ on SuperNova diffractometer (Agilent) with a CCD detector and $\mathrm{Cu}-\mathrm{K}_{\alpha}$ radiation. The crystal data were processed with CrysAlisPro (data collection, cell refinement, and data reduction) [57]. The crystal structure was solved using direct methods with SHELXD and refined with SHELXL [58]. All $\mathrm{H}$ atoms were located in electron density difference maps. C-bonded hydrogen atoms were constrained to idealized positions with $\mathrm{C}-\mathrm{H}$ distances fixed at $0.98-1.00 \AA$ and with $U_{\text {iso }}(\mathrm{H})=1.5 U_{\mathrm{eq}}(\mathrm{C})$ for methyl hydrogen atoms and $U_{\text {iso }}(\mathrm{H})=1.2 U_{\text {eq }}(\mathrm{C})$ for others. PLATON software [59] was used to validate the crystallographic data.

Crystal Data. $\mathrm{C}_{9} \mathrm{H}_{15} \mathrm{NO}, M_{r}=153.22$, colourless prism, $0.46 \times$ $0.28 \times 0.21 \mathrm{~mm}^{3}$, monoclinic, space group $P 2_{1} / c, a=20.8638$ (2) $\AA, b=7.24526$ (8) $\AA, c=11.47997$ (13) $\AA, \beta=105.3447$ (12) , $V=1673.49(3) \AA^{3}, Z=8, \rho_{\text {calcd }}=1.216 \mathrm{~g} \cdot \mathrm{cm}^{-3}, \mu=0.62 \mathrm{~mm}^{-1}$, $F(000)=672, R_{1}=0.037, w R^{2}=0.092,3382$ independent reflections, $\theta_{\max }=74.5^{\circ}, \theta_{\min }=4.4^{\circ}$, and 201 parameters are included. CCDC-1014754 contains the supplementary crystallographic data for this paper. These data can be obtained free of charge from The Cambridge Crystallographic Data Centre via https://www.ccdc.cam.ac.uk/data_request/cif.

9-Methyl-9-azabicyclo[3.3.1]nonan-3-one hemihydrate (2.(1) 2) $\left.\mathrm{H}_{2} \mathrm{O}\right)$. Crystals suitable for X-ray diffraction study were obtained at $255 \mathrm{~K}$ by slow evaporation from a mixture of $n$-hexane-ethyl ether (ratio $5: 1$ ). The X-ray diffraction data were collected at $100(2) \mathrm{K}$ on SuperNova diffractometer (Agilent) with a CCD detector and $\mathrm{Mo}-K_{\alpha}$ radiation. The crystal data were processed with CrysAlisPro (data collection, cell refinement, and data reduction) [57]. The crystal structure was solved using direct methods with SHELXD and refined with SHELXL [58]. All $\mathrm{H}$ atoms were located in electron density difference maps. C-bonded hydrogen atoms were constrained to idealized positions with $\mathrm{C}-\mathrm{H}$ distances fixed at $0.98-1.00 \AA$ and with $U_{\text {iso }}(\mathrm{H})=1.5 U_{\text {eq }}(\mathrm{C})$ for methyl hydrogen atoms and $U_{\text {iso }}(\mathrm{H})=1.2 U_{\text {eq }}(\mathrm{C})$ for others. The positions and atomic displacement parameters of water hydrogen atoms were freely refined. PLATON software [59] was used to validate the crystallographic data.

Crystal Data. $\left(\mathrm{C}_{9} \mathrm{H}_{15} \mathrm{NO}\right)_{2} \cdot \mathrm{H}_{2} \mathrm{O}, M_{r}=324.46$, colourless prism, $0.34 \times 0.19 \times 0.09 \mathrm{~mm}^{3}$, orthorhombic space group $P 2{ }_{1} 2{ }_{1} 2_{1}, a=6.77816(14) \AA, b=10.1532(3) \AA, c=25.8827(4) \AA$,
$V=1781.25(7) \AA^{3}, Z=4, \rho_{\text {calcd }}=1.210 \mathrm{~g} \cdot \mathrm{cm}^{-3}, \mu=0.08 \mathrm{~mm}^{-1}$, $F(000)=712, R_{1}=0.038, w R^{2}=0.098,2542$ independent reflections, $\theta_{\max }=28.3^{\circ}, \theta_{\min }=3.1^{\circ}$, and 218 parameters are included. CCDC-1012809 contains the supplementary crystallographic data for this paper. These data can be obtained free of charge from The Cambridge Crystallographic Data Centre via https://www.ccdc.cam.ac.uk/data_request/cif.

Computational Methods. Electronic structure calculations were carried out using the GAUSSIAN 09 (G09) [60] suite of programs. To account for the solvent effect, the polarizable continuum model (CPCM [61]) was applied as implemented in the Gaussian 09 package. All reported results for stable molecules and transition states were obtained for the lowest energy conformer of a given species. Normal mode analysis was performed at each stationary point to ensure that the stable structure had zero imaginary vibrational frequency whereas the transition state (TS) structure had one imaginary vibrational frequency, whose mode corresponds to the reaction coordinate. Intrinsic Reaction Coordinate (IRC) calculations have been systematically performed at the B3LYP/6-31G(d) level to ensure that the computed TS's connect the desired reactants and products. A self-consistent reaction field (SCRF) approach using CPCM [61, 62] settings with the solvent explicitly set to water was used to model the influence of implicit solvation.

\section{Competing Interests}

The authors declare that they have no competing interests.

\section{Acknowledgments}

The work was supported by the University of Bialystok (BST125 ) and the National Science Center, Poland (Grant no. 2014/13/D/ST5/02871 and Grant no. 2014/15/B/ST5/04695). The authors thank the Computational Centre of the University of Warsaw (ICM, Grant G33-03) and the Computer Centre of University of Bialystok (UCO, Grant GO-008) for providing access to the supercomputer resources and the GAUSSIAN 09 program. The X-ray diffractometer was funded by EFRD as part of the Operational Programme Development of Eastern Poland 2007-2013 (Project no. POPW.01.03.00-20-034/09-00).

\section{References}

[1] B. M. Trost and C. S. Brindle, "The direct catalytic asymmetric aldol reaction," Chemical Society Reviews, vol. 39, no. 5, pp. 1600-1632, 2010.

[2] B. List, R. A. Lerner, and C. F. Barbas III, "Proline-catalyzed direct asymmetric aldol reactions," Journal of the American Chemical Society, vol. 122, no. 10, pp. 2395-2396, 2000.

[3] S. G. Zlotin, A. S. Kucherenko, and I. P. Beletskaya, "Organocatalysis of asymmetric aldol reaction. Catalysts and reagents," Russian Chemical Reviews, vol. 78, no. 8, pp. 737-784, 2009.

[4] S. Mukherjee, J. W. Yang, S. Hoffmann, and B. List, "Asymmetric enamine catalysis," Chemical Reviews, vol. 107, no. 12, pp. 54715569, 2007. 
[5] A. Heine, G. DeSantis, J. G. Luz, M. Mitchell, C.-H. Wong, and I. A. Witson, "Observation of covalent intermediates in an enzyme mechanism at atomic resolution," Science, vol. 294, no. 5541, pp. 369-374, 2001.

[6] M. Markert, M. Mulzer, B. Schetter, and R. Mahrwald, "Aminecatalyzed direct aldol addition," Journal of the American Chemical Society, vol. 129, no. 23, pp. 7258-7259, 2007.

[7] J. Paradowska, M. Rogozińska, and J. Mlynarski, "Direct asymmetric aldol reaction of hydroxyacetone promoted by chiral tertiary amines," Tetrahedron Letters, vol. 50, no. 14, pp. 16391641, 2009.

[8] C. D. Gutsche, R. S. Buriks, K. Nowotny, and H. Grassner, "Tertiary amine catalysis of the aldol condensation," Journal of the American Chemical Society, vol. 84, no. 19, pp. 3775-3777, 1962.

[9] C. D. Gutsche, D. Redmore, R. S. Buriks, K. Nowotny, H. Grassner, and C. W. Armbruster, "Base-catalyzed triose condensations," Journal of the American Chemical Society, vol. 89, no. 5, pp. 1235-1245, 1967.

[10] P. M. Pihko, K. M. Laurikainen, A. Usano, A. I. Nyberg, and J. A. Kaavi, "Effect of additives on the proline-catalyzed ketonealdehyde aldol reactions," Tetrahedron, vol. 62, no. 2-3, pp. 317328, 2006.

[11] M. S. Abaee, M. M. Mojtahedi, G. F. Pasha et al., "Switching the reactivity of dihydrothiopyran-4-one with aldehydes by aqueous organocatalysis: Baylis-Hillman, aldol, or aldol condensation reactions," Organic Letters, vol. 13, no. 19, pp. 52825285, 2011.

[12] P. H.-Y. Cheong, C. Y. Legault, J. M. Um, N. Çelebi-Ölçüm, and K. N. Houk, "Quantum mechanical investigations of organocatalysis: mechanisms, reactivities, and selectivities," Chemical Reviews, vol. 111, no. 8, pp. 5042-5137, 2011.

[13] R. Lazny, M. Sienkiewicz, T. Olenski, Z. Urbanczyk-Lipkowska, and P. Kalicki, "Approaches to the enantioselective synthesis of ferrugine and its analogues," Tetrahedron, vol. 68, no. 39, pp. 8236-8244, 2012.

[14] M. Sienkiewicz, U. Wilkaniec, and R. Lazny, "Enantioselective route to ferrugine and its methyl analogue via aldol deoxygenation," Tetrahedron Letters, vol. 50, no. 51, pp. 7196-7198, 2009.

[15] J. C. Lee, K. Lee, and J. K. Cha, "Enantioselective synthesis of unnatural (S)-(+)-cocaine," Journal of Organic Chemistry, vol. 65, no. 15, pp. 4773-4775, 2000.

[16] G. P. Pollini, S. Benetti, C. De Risi, and V. Zanirato, "Synthetic approaches to enantiomerically pure 8-azabicyclo[3.2.1] octane derivatives," Chemical Reviews, vol. 106, no. 6, pp. 2434-2454, 2006.

[17] R. Lazny, A. Nodzewska, and I. Tomczuk, "Spontaneous and diastereoselective aldol reactions of cyclic $\beta$-amino ketones in the presence of water," Tetrahedron Letters, vol. 52, no. 43, pp. 5680-5683, 2011.

[18] R. Lazny, K. Wolosewicz, P. Zielinska, Z. Urbanczyk-Lipkowska, and P. Kalicki, "Diastereo- and enantioselective aldol reaction of granatanone (pseudopelletierine)," Tetrahedron, vol. 67, no. 48, pp. 9433-9439, 2011.

[19] M. Majewski and R. Lazny, "Synthesis of tropane alkaloids via enantioselective deprotonation of tropinone," Journal of Organic Chemistry, vol. 60, no. 18, pp. 5825-5830, 1995.

[20] R. Lazny and A. Nodzewska, "Synthesis of polymeric supports with spacer-modified triazene linkers: aldol and Grignard reactions of immobilized nortropinone," Tetrahedron Letters, vol. 44, no. 12, pp. 2441-2444, 2003.
[21] R. Lazny, A. Nodzewska, and M. Sienkiewicz, "Studies on aldol reactions of nortropinone derivatives in solution and on solid phase," Letters in Organic Chemistry, vol. 7, no. 1, pp. 21-26, 2010.

[22] R. Lazny, A. Nodzewska, K. Sidorowicz, and P. Kalicki, "Determination of the relative configuration of tropinone and granatanone aldols by using TBDMS ethers," Beilstein Journal of Organic Chemistry, vol. 8, pp. 1877-1883, 2012.

[23] A. Nodzewska, A. Bokina, K. Romanowska, and R. Lazny, "Environmentally benign diastereoselective synthesis of granatane and tropane aldol derivatives," RSC Advances, vol. 4, no. 56, pp. 29668-29681, 2014.

[24] R. Lazny, A. Ratkiewicz, A. Nodzewska, and J. Wysocka, "A DFT study of the origins of the stereoselectivity in the aldol reaction of bicyclic amino ketones in the presence of water," Tetrahedron Letters, vol. 53, no. 44, pp. 5871-5874, 2012.

[25] O. V. Dolomanov, L. J. Bourhis, R. J. Gildea, J. A. K. Howard, and H. Puschmann, "OLEX2: a complete structure solution, refinement and analysis program," Journal of Applied Crystallography, vol. 42, no. 2, pp. 339-341, 2009.

[26] X. Zhang and K. N. Houk, "Acid/base catalysis by pure water: the aldol reaction," Journal of Organic Chemistry, vol. 70, no. 24, pp. 9712-9716, 2005.

[27] E. Iglesias, “Tautomerization of 2-acetylcyclohexanone. 1. Characterization of keto-enol/enolate equilibria and reaction rates in water," Journal of Organic Chemistry, vol. 68, no. 7, pp. 26802688, 2003.

[28] G. Alagona, C. Ghio, and P. I. Nagy, "The catalytic effect of water on the keto-enol tautomerism. Pyruvate and acetylacetone: a computational challenge," Physical Chemistry Chemical Physics, vol. 12, no. 35, pp. 10173-10188, 2010.

[29] S. Yamabe, N. Tsuchida, and K. Miyajima, "Reaction paths of keto-enol tautomerization of $\beta$-diketones," The Journal of Physical Chemistry A, vol. 108, no. 14, pp. 2750-2757, 2004.

[30] R. J. Cantlin, J. Drake, and R. W. Nagorski, "Ring strain and its effect on the rate of the general-base catalyzed enolization of cyclobutanone," Organic Letters, vol. 4, no. 14, pp. 2433-2436, 2002.

[31] E. D. Raczyńska, W. Kosińska, B. Ośmiałowski, and R. Gawinecki, "Tautomeric equilibria in relation to Pi-electron delocalization," Chemical Reviews, vol. 105, no. 10, pp. 3561-3612, 2005.

[32] J. K. Coward and T. C. Bruice, "Intramolecular amine-catalyzed ketone enolization. A search for concerted intramolecular general-base, general-acid catalysis," Journal of the American Chemical Society, vol. 91, no. 19, pp. 5339-5345, 1969.

[33] S. O. C. Mundle, G. W. Howe, and R. Kluger, "Origins of steric effects in general-base-catalyzed enolization: solvation and electrostatic attraction," Journal of the American Chemical Society, vol. 134, no. 2, pp. 1066-1070, 2012.

[34] M. Majewski, R. Lazny, and A. Ulaczyk, "Enantioselective ring opening of tropinone. a new entry into tropane alkaloids," Canadian Journal of Chemistry, vol. 75, no. 6, pp. 754-761, 1997.

[35] P. Écija, M. Vallejo-López, L. Evangelisti et al., "O-H-N and $\mathrm{C}-\mathrm{H}-\mathrm{O}$ hydrogen bonds control hydration of pivotal tropane alkaloids: tropinone- $\mathrm{H}_{2} \mathrm{O}$ complex," ChemPhysChem, vol. 15, no. 5, pp. 918-923, 2014.

[36] R. Lazny, A. Ratkiewicz, A. Nodzewska, A. Wynimko, and L. Siergiejczyk, "Determination of the $N$-methyl stereochemistry in tropane and granatane derivatives in solution: a computational and NMR spectroscopic study," Tetrahedron, vol. 68, no. 31, pp. 6158-6163, 2012. 
[37] K. Sidorowicz, A. Ratkiewicz, A. Nodzewska, and R. Lazny, "Determination of the $\mathrm{N}$-invertomer stereochemistry in $\mathrm{N}$ substituted nortropanones and norgranatanones using computational and NMR methods," Comptes Rendus Chimie, vol. 18, no. 6, pp. 693-704, 2015.

[38] K. Sidorowicz, R. Lazny, A. Nodzewska et al., "Isomerisation and configurational assignment of 2-alkyltropane and 2alkylgranatane derived hydrazones," Tetrahedron, vol. 71, no. 32, pp. 5148-5158, 2015.

[39] R. J. Staples, Y. Qi, and Z. Kristallogr, "Crystal structure of 8methyl-8-azabicyclo(3,2,1)octan-3-one, $\mathrm{C}_{8} \mathrm{H}_{13} \mathrm{NO}$," New Crystal Structures, vol. 222, pp. 225-226, 2007.

[40] D. Cremer and J. A. Pople, "General definition of ring puckering coordinates," Journal of the American Chemical Society, vol. 97, no. 6, pp. 1354-1358, 1975.

[41] A. D. Becke, "Density-functional exchange-energy approximation with correct asymptotic behavior," Physical Review A, vol. 38, no. 6, pp. 3098-3100, 1988.

[42] R. Ditchfield, W. J. Hehre, and J. A. Pople, "Self-consistent molecular-orbital methods. IX. An extended gaussian-type basis for molecular-orbital studies of organic molecules," The Journal of Chemical Physics, vol. 54, no. 2, pp. 724-728, 1971.

[43] A. D. McLean and G. S. Chandler, "Contracted Gaussian basis sets for molecular calculations. I. Second row atoms, $Z=11-18$," The Journal of Chemical Physics, vol. 72, no. 10, pp. 5639-5648, 1980.

[44] A. D. Becke, "A new mixing of Hartree-Fock and local densityfunctional theories," The Journal of Chemical Physics, vol. 98, no. 2, pp. 1372-1377, 1993.

[45] T. H. Dunning, "Gaussian basis sets for use in correlated molecular calculations. I. The atoms boron through neon and hydrogen," The Journal of Chemical Physics, vol. 90, no. 2, pp. 1007-1023, 1989.

[46] Y. Zhao and D. G. Truhlar, "The M06 suite of density functionals for main group thermochemistry, thermochemical kinetics, noncovalent interactions, excited states, and transition elements: two new functionals and systematic testing of four M06-class functionals and 12 other functionals," Theoretical Chemistry Accounts, vol. 120, no. 1, pp. 215-241, 2008.

[47] W. M. C. Sameera and D. A. Pantazis, "A hierarchy of methods for the energetically accurate modeling of isomerism in monosaccharides," Journal of Chemical Theory and Computation, vol. 8, no. 8, pp. 2630-2645, 2012.

[48] C. Allemann, J. M. Um, and K. N. Houk, "Computational investigations of the stereoselectivities of proline-related catalysts for aldol reactions," Journal of Molecular Catalysis A: Chemical, vol. 324, no. 1-2, pp. 31-38, 2010.

[49] J. P. Guthrie and P. A. Cullimore, "The enol content of simple carbonyl compounds: a thermochemical approach," Canadian Journal of Chemistry, vol. 57, no. 2, pp. 240-248, 1979.

[50] Y. Chiang, A. J. Kresge, Y. S. Tang, and J. Wirz, "The pKa and keto-enol equilibrium constant of acetone in aqueous solution," Journal of the American Chemical Society, vol. 106, no. 2, pp. 460-462, 1984.

[51] K. Brzezinski, R. Lazny, M. Sienkiewicz, S. Wojtulewski, and Z. Dauter, "(2R)-8-Benzyl-2-[(S)-hydroxy(phenyl)-methyl]-8azabicyclo[3.2.1]octan-3-one," Acta Crystallographica Section E: Structure Reports Online, vol. 68, no. 1, pp. o149-o150, 2012.

[52] R. Lazny, K. Wolosewicz, Z. Dauter, and K. Brzezinski, "(1RS,2SR,5SR)-9-Benzyl-2-[(1RS)-1-hydroxybenzyl]-9azabicyclo[3.3.1] nonan-3-one from synchrotron data, Acta Crystallographica, vol. E68, part 5, Article ID o1367, 2012.
[53] K. Brzezinski, R. Lazny, A. Nodzewska, and K. Sidorowicz, "Relative configuration, absolute configuration and absolute structure of three isomeric 8-benzyl-2-[(4-bromophenyl)(hydroxy) methyl]-8-azabicyclo[3.2.1] octan-3-ones," Acta Crystallographica Section C: Crystal Structure Communications, vol. 69, no. 3, pp. 303-306, 2013.

[54] G. Zheng, L. P. Dwoskin, and P. A. Crooks, "The preparation of 2-arylmethylidene-8-methyl-8-azabicyclo[3.2.1] octan-3ones," Synthetic Communications, vol. 34, no. 11, pp. 1931-1942, 2004.

[55] D. E. Ward, M. Sales, and P. K. Sasmal, "Syn-anti isomerization of aldols by enolization," Organic Letters, vol. 3, no. 23, pp. 3671$3673,2001$.

[56] D. E. Ward, M. Sales, and P. K. Sasmal, "Syn-anti isomerization of aldols by enolization," Journal of Organic Chemistry, vol. 69, no. 14, pp. 4808-4815, 2004.

[57] CrysAlisPro, Agilent Technologies, Yarnton, UK, 2011.

[58] G. M. Sheldrick, "A short history of SHELX," Acta Crystallographica A, vol. 64, pp. 112-122, 2008.

[59] A. L. Spek, "Structure validation in chemical crystallography," Acta Crystallographica Section D Biological Crystallography, vol. 65, no. 2, pp. 148-155, 2009.

[60] M. J. Frisch, G. W. Trucks, H. B. Schlegel et al., Gaussian 09, Revision A.1, Gaussian Inc, Wallingford, Conn, USA, 2009.

[61] V. Barone and M. Cossi, "Quantum calculation of molecular energies and energy gradients in solution by a conductor solvent model," Journal of Physical Chemistry A, vol. 102, no. 11, pp. 1995-2001, 1998.

[62] V. Barone, M. Cossi, and J. Tomasi, "Geometry optimization of molecular structures in solution by the polarizable continuum model," Journal of Computational Chemistry, vol. 19, no. 4, pp. 404-417, 1998. 

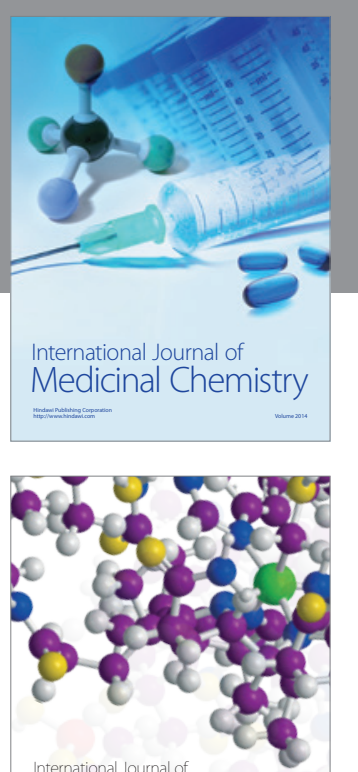

Carbohydrate Chemistry

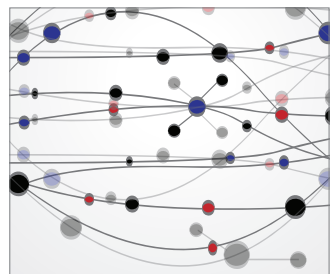

The Scientific World Journal
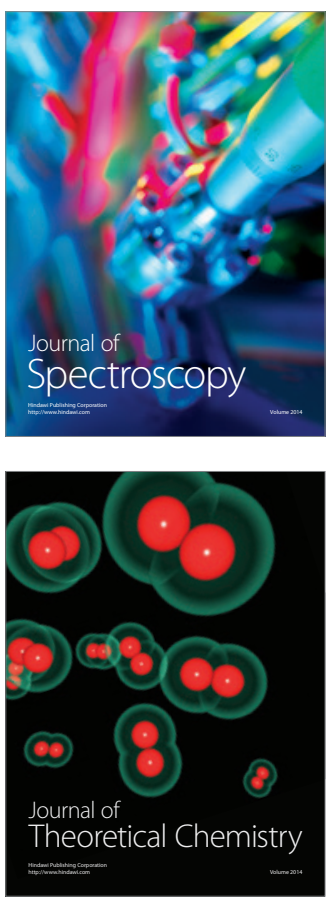
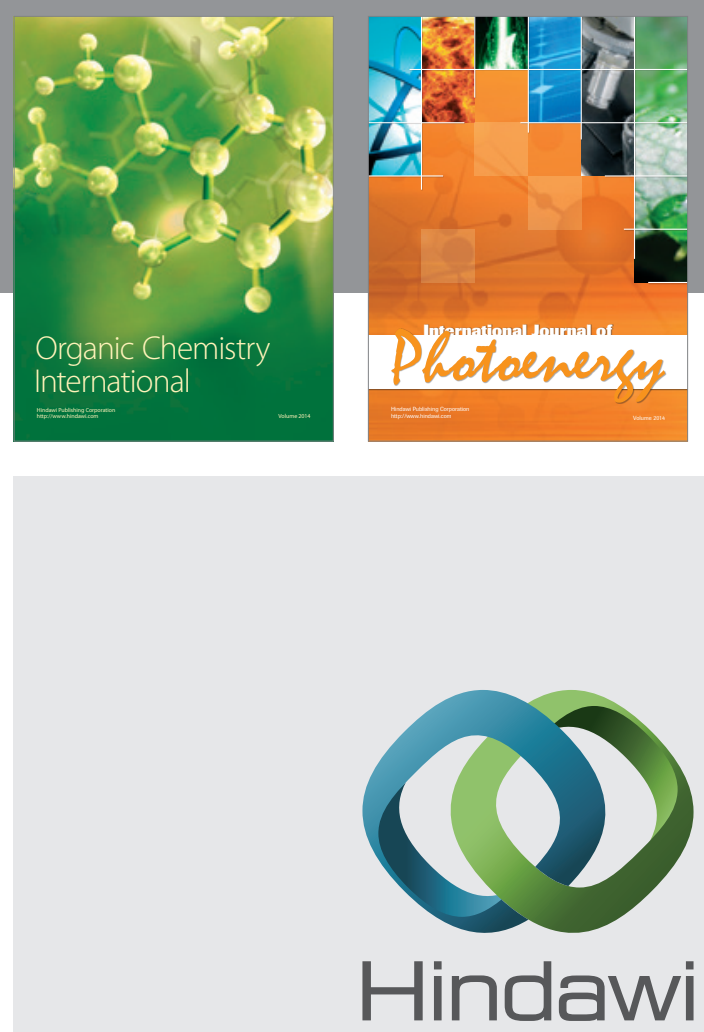

Submit your manuscripts at

http://www.hindawi.com

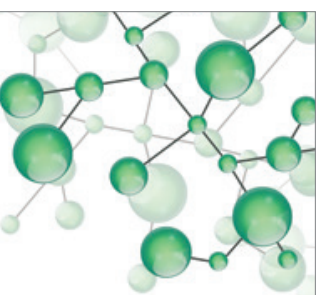

International Journal of

Inorganic Chemistry

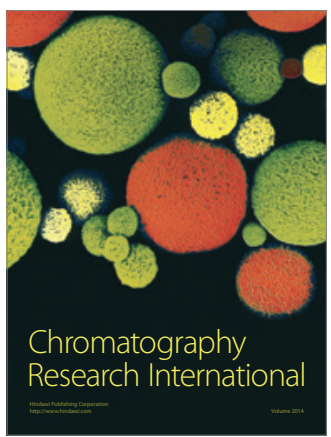

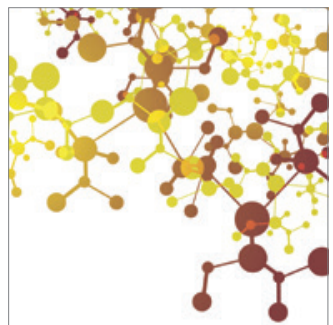

Applied Chemistry
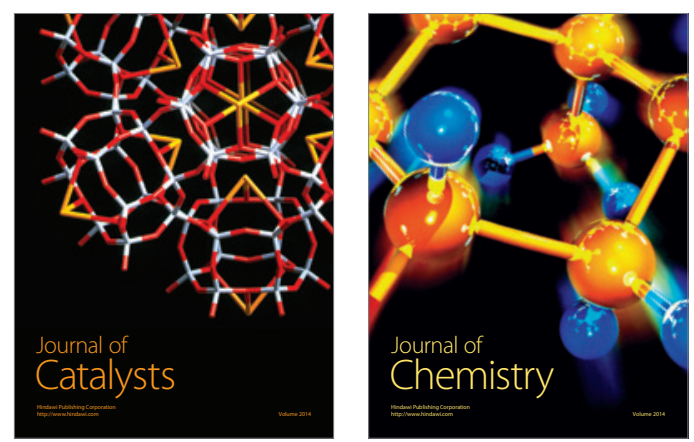
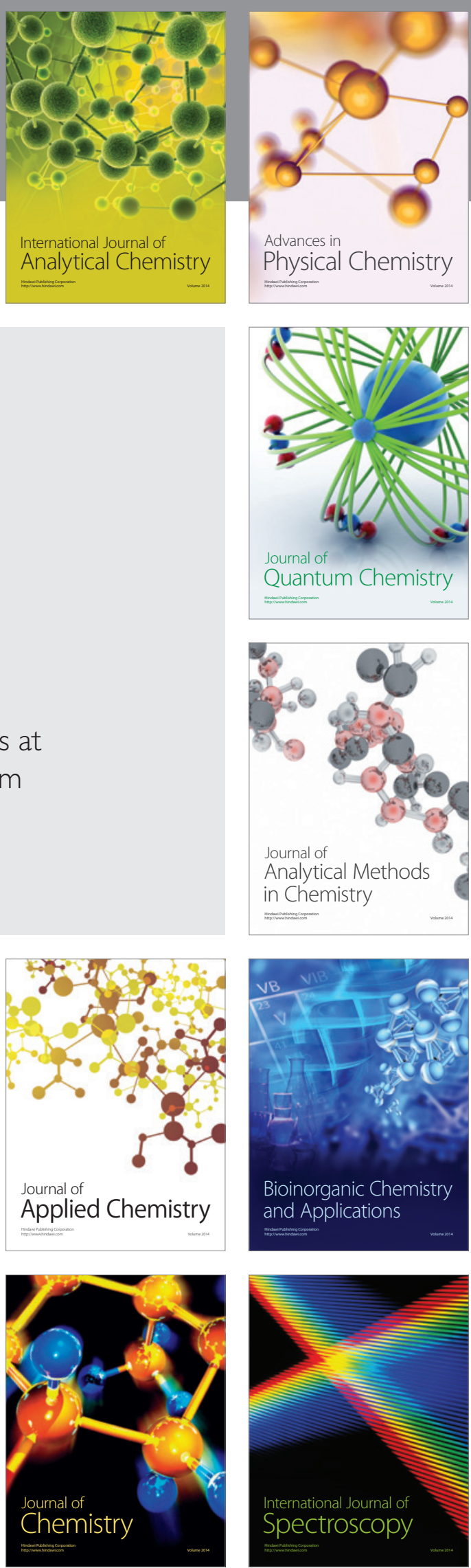